Revista de la Facultad de Geografía e Historia, núm. 3, 1988, págs. 39-72

\title{
Algunas consideraciones sobre los movimientos migratorios interregionales en la CEE
}

\author{
M. ${ }^{a}$ Victoria AzCARate LuXán y PILAR Borderías URibeondo
}

En nuestros dias existe una preocupación generalizada por conocer cuáles serán las repercusiones de nuestra adhesión a la CEE, tanto a nivel económico como sociopolítico. Esta inquietud es la que nos ha llevado a analizar uno de los hechos que se ha visto más directamente influido a nivel social: el de los movimientos migratorios.

Los movimientos migratorios, constante histórica de distinta magnitud en función de las características particulares del momento considerado y de las vicisitudes socioeconómicas de los países que entran en juego como emisores o como receptores, parece que pueden experimentar modificaciones en sus características a partir de la última ampliación de la CEE. España, país que tradicionalmente aportaba un gran potencial de mano de obra, fue uno de los más afectados por el retorno de sus trabajadores emigrantes tras la crisis económica de los años 70; este descenso en la demanda de mano de obra se agudizó por la existencia de unos convenios menos ventajosos en materia de emigración que los establecidos con países del Tercer Mundo. En el momento actual, en que parece estar cambiando algo la situación al comenzar una cierta recuperación económica, nuestra adhesión a la vida comunitaria supondrá la incorporación a un mercado de trabajo más ámplio que actuará evidentemente en un doble sentido, al mismo tiempo que deberá significar una mejora en los convenios a todos los niveles; no obstante, estas posibilidades quedarán supeditadas a las condiciones socioeconómicas generales de los distintos países comunitarios. Por ello hemos creído intere- 
sante conocer cuál es la situación en materia de migración dentro del marco al que nos incorporamos.

El análisis de la situación actual comunitaria en materia de migración nos ha llevado a plantearnos una serie de hechos que serán objeto de un pormenorizado estudio, algunos de cuyos primeros resultados presentamos en este artículo a modo de introducción.

Son muchos los factores que generalmente inciden en los movimientos migratorios, entre los que hemos seleccionado los más significativos, analizando una serie de variables que hemos puesto en correlación.

Las variables consideradas a nivel regional son las siguientes:

- variables demográficas:

- Población total

- Saldo migratorio total

- Saldo migratorio interregional

- variables socieconómicas:

- Empleo según sectores de actividad (en \% del total de personas ocupadas)

- Indice de paro (en \% de la fuerza de trabajo)

- Producto Interior Bruto por habitante (en \% de la media comunitaria en paridades del poder adquisitivo).

- variables de calidad de vida:

- Indicadores de consumo (consumo doméstico de electricidad en $\mathrm{Kwh} / \mathrm{hab}$; $n .^{\circ}$ de abonados telefónicos/ 1.000 hab.; $n .{ }^{\circ}$ de televisores/1.000 hab.; $n .^{\circ}$ de coches particulares/1.000 hab.; $n .^{\circ}$ de motociclos $/ 1.000$ hab.) 
- Indicadores de equipamiento y confort de las viviendas $\left(n{ }^{\circ}\right.$ de viviendas/1.000 hab.; porcentaje de viviendas con baño/ducha; porcentaje de viviendas con calefacción central).

- Indicadores de salud ( $n .{ }^{\circ}$ de médicos/1.000 hab.; $n .{ }^{\circ}$ de farmacéuticos/1.000 hab.; . $^{\circ}$ de dentistas/1.000 hab.; $n .^{\circ}$ de camas de hospital/1.000 hab.).

Estos datos se refieren principalmente a las regiones de nivel II, división regional utilizada por los informes de la Comisión de la CEE, basada en la Nomenclatura de las Unidades Territoriales y Estadísticas (NUTS) y acordada entre el Eurostat y los Estados miembros con el fin de obtener un marco de referencia uniforme para las estadísticas regionales (Fig. 1).

Es importante precisar que la interpretación de todos estos datos cuenta con los clásicos problemas que presentan la mayoría de las informaciones estadísticas, máxime cuando éstos son tan diversos y además procedentes de distintos países: lagunas en la información de algunas regiones; selección de variables en función de la información disponible; problemas en la comparabilidad de los datos, especialmente de los sociales, que están influidos por diferentes legislaciones, definición de las variables, etc. No obstante, una prudente interpretación de los datos permite una aproximación significativa a la realidad regional del momento estudiado. Así pues, los aspectos tratados en este artículo se centran en:

- Situación actual del balance migratorio en las regiones comunitarias.

- Relaciones existentes entre el saldo migratorio y los factores económicos, laborales y de bienestar.

\section{MOVIMIENTOS MIGRATORIOS INTERNACIONALES E INTERREGIONALES}

Es de sobra conocido por todos el papel fundamental que ha desempeñado la fuerza de trabajo emigrante, procedente de los países de la Europa periférica y especialmente mediterránea, en el rápido crecimiento económico de postguerra en los paises de capitalismo avanzado de Europa occidental. 
Sin embargo, este proceso quedó atenuado tras la primera crisis del petróleo de 1973, al variar la política de los países receptores a causa de la recesión económica.

Si analizamos la evolución de los saldos migratorios internacionales de cada uno de los Estados miembros, desde 1960 hasta 1984 (Fig. 2), vemos cómo se marcan claramente los momentos de crisis y de apertura, con una neta tendencia a la disminución de la movilidad en los últimos años.

Momentos como el retorno a Francia de los repatriados tras la independencia de Argelia, la entrada de mano de obra turca en la RFA, la vuelta de los holandeses de Indonesia, o el retorno de los repatriados a Portugal provenientes de las antiguas colonias, establecen un marcado cambio de signo en la curva de las migraciones.

A partir de la década de los 70 , países que habian presentado tradicionalmente un saldo migratorio negativo, como es el caso de Italia, Irlanda, Grecia, España y Portugal, pasan a tener un signo migratorio marcadamente positivo. Contrariamente a todos estos bruscos cambios de signo experimentados en la mayoría de los paises, el Reino Unido ha mantenido una constante en su saldo migratorio, tanto en cuanto al signo como en cuanto a los valores alcanzados por su emigración.

Analizando la procedencia de los inmigrantes en cada pais, se observa que la inmigración intracomunitaria es predominante en Irlanda, Bélgica, Luxemburgo, Grecia y España (Fig. 3), mientras que en el resto de los paises miembros el mayor porcentaje de la inmigración es extracomunitaria, proviniendo en su mayor parte de paises del Tercer Mundo, favorecidos por factores tan importantes como representar una mano de obra barata y ser una población menos exigente laboralmente (nótese, por ejemplo, los altos porcentajes que representan los residentes extranjeros procedentes de Africa y Turquia en varios países de la Comunidad).

Junto al descenso general de los movimientos migratorios internacionales, la migración interregional dentro de la Comunidad ha sufrido el mismo proceso, descendiendo por debajo del 0,25 por 100 en los años 80 . No obstante, los movimientos migratorios interregionales dentro de un mismo pais han sido muy superiores a los movimientos migratorios entre paises. Así, las diferencias migratorias que se aprecian entre los países comunitarios se acentúan al estudiar los movimientos interregionales, tanto por la gran movilidad que se aprecia en algunas regiones, como por la oscilación en sus signos migratorios. 
Analizando los saldos migratorios internacionales, según datos de 1986, en cada uno de los países miembros, se observan diferentes tendencias (Fig. 4). Portugal, pais de tradición emigratoria, presenta un cambio de situación al convertirse hoy dia en un país de inmigración. En España destacan como regiones de neta emigración las dos Castillas, Extremadura y el País Vasco. Italia ha visto frenada la tradicional emigración de sus regiones meridionales y hoy dia la mayoría de ellas reciben inmigrantes, excepto Basilicata. El mismo fenómeno se observa en Francia, donde las regiones del Oeste y las meridionales experimentan en la actualidad una acentuada inmigración, mientras que regiones como lle-de-France, Nord-Pas-de-Calais, Champagne-Ardenne, Lorraine y Normandie pierden población. En Grecia tan sólo gana población la región central. La RFA, país que tradicionalmente ha sido un importante foco de atracción de mano de obra, presenta en la actualidad una emigración bastante generalizada, destacando sobre todo la región de Nordrhein-Westfalen. En los Paises Bajos el 63 por 100 de las regiones presentan saldos de emigración neta, a excepción de Gelderland (que alcanza el mayor porcentaje de inmigración del pais), Utrecht, Drenthe y Zuid-Holland. En Bélgica destaca la provincia de Namur con el mayor saldo migratorio positivo de la nación, mientras que el resto de las regiones mantiene unos valores próximos a cero, con distinto signo según los casos. Por último, Irlanda continúa con unas acentuadas tasas de emigración en todo su territorio, y el Reino Unido presenta una marcada tendencia a la inmigración en su sector meridional, mientras que la emigración es predominante en el Norte del país.

Ahora bien, al analizar los movimientos migratorios interregionales se producen, en algunas regiones, importantes modificaciones con respecto a las migraciones totales (Fig. 5).

En el caso de España cambia de signo el saldo migratorio de Madrid, Cataluña, Asturias, Castilla-La Mancha y Extremadura, mientras que la emigración del País Vasco se acentúa y se incrementa la inmigración en la Comunidad Valenciana. Dentro de las regiones francesas es de destacar la acentuación del saldo emigratorio en las regiones de lle-de-France y NordPas-de-Calais, y del saldo inmigratorio en Provence-Alpes-Côte d'Azur, así como el cambio de signo migratorio experimentado por Alsace y FrancheComte. El Reino Unido presenta un caso especialmente curioso al experimentar todas sus regiones un cambio de signo entre los saldos migratorios internacionales e interregionales. Así, las regiones meridionales, globalmente inmigratorias, a nivel interregional padecen un acusado descenso de población. Lo contrario se aprecia en las regiones del Norte donde, aun- 
que la tónica general es de un proceso de emigración, a escala interregional están acogiendo población.

En la República Federal Alemana las modificaciones más significativas se aprecian en las regiones de Bayern y Baden-Württemberg, cuyos saldos migratorios cambian de signo, siendo también de destacar la mayor incidencia de la emigración a nivel internacional en las regiones de NordrheinWestfalen y Hessen.

Finalmente, la región Sur de Italia, que en los últimos años presenta unos saldos migratorios positivos, muestra todavía una cierta tendencia a la emigración interregional.

En definitiva, se observa que los movimientos migratorios en la CEE siguen experimentando cambios. Durante largo tiempo las migraciones regionales se dirigieron hacia las grandes capitales y hacia las regiones desarrolladas a raíz de la revolución industrial, pero hoy día, a partir de la crisis energética, estos movimientos están perdiendo importancia e incluso han cambiado de signo. Así, podemos observar cómo determinadas regiones que cuentan con un nivel de renta alto, pero ya con síntomas de cierta debilidad, y con un paro desproporcionalmente elevado, arrojan un mayor saldo emigratorio al encontrarse afectadas en la actualidad por problemas específicos de reconversión industrial (siderurgia, construcción naval y textil).

Con respecto a las áreas urbanas,es necesario establecer una diferenciación según su situación geográfica. Por una parte, en las regiones periféricas meridionales se sigue observando la tradicional atracción hacia las zonas urbanas en detrimento de las regiones vecinas; por otra parte, las áreas metropolitanas de las regiones septentrionales de la Comunidad acusan un fenómeno opuesto y se despueblan en favor de sus hinterlands rurales.

\section{ALGUNOS INDICADORES SOCIOECONOMICOS EN RELACION CON LOS MOVIMIENTOS MIGRATORIOS}

Son muchos los factores que repercuten en los movimientos migratorios, variando la incidencia de cada uno de ellos en función de las desigualdades 
existentes entre las distintas regiones: disparidades de tipo socio-económico, de comportamiento, de condiciones de vida, etc., que la política regional comunitaria trata de paliar. La influencia prioritaria de uno $u$ otro factor varía notablemente en función de las características propias de cada región, por lo que unas referencias generales no resultan significativas, siendo necesario hacer mención individualizada de cada uno de ellos.

En los estudios realizados sobre migraciones se hace especial hincapié en la estrecha relación de éstas con diversos factores económicos y de nivel de vida, al ser un hecho generalmente aceptado que las migraciones laborales son motivadas por una mejora económica. Según datos estadísticos de 1986, al correlacionar el saldo migratorio por países con cada una de las variables seleccionadas, vemos cómo a nivel general no existe una acusada correlación (anexo I. Eur 12), apreciándose tan sólo una débil correlación con alguno de los indicadores de calidad de vida. No obstante, este hecho varia notablemente al analizar las correlaciones a nivel regional (anexos II al X).

El potencial económico y el paro son dos factores socioeconómicos de gran repercusión sobre los flujos migratorios, los cuales, en líneas generales, presentan entre si una correlación negativa (a excepción de los Países Bajos y la RFA).

Por lo que respecta al PIB, las disparidades son muy acusadas; a nivel nacional, el valor alcanzado por este indicador oscila entre el máximo de la RFA y Dinamarca ( $117 \%$ /hab.) y el mínimo de Portugal ( $55 \% /$ hab.), pero los valores regionales llegan a alcanzar una diferencia de hasta un 197 por $100(244 \%$ en Groningen -Países Bajos-y $47 \%$ en Extremadura -España-). En líneas generales, se constata a nivel nacional que son precisamente los paises de la periferia meridional y occidental de la Comunidad los que se encuentran por debajo de la media comunitaria. Si descendemos a un nivel regional, de nuevo son las regiones más meridionales de la periferia comunitaria las que presentan unos valores más bajos de renta per capita, junto con alguna que otra región aislada del centro y norte de la Comunidad, correspondientes en su mayor parte a zonas que en la actualidad padecen graves problemas de reajuste estructural. Las correlaciones estadísticas establecidas muestran solamente una correlación significativa entre el PIB y el saldo migratorio en Dinamarca $(-0,77)$, RFA $(-0,41)$ y Reino Unido $(0,41)$, siendo despreciable en el resto de los paises.

El paro, en los últimos años, ha experimentado en todos los países un progresivo incremento, debido a la crisis económica y a la incorporación al 
mercado de trabajo de la mano de obra femenina y de los jóvenes incorporados a la población activa. Para las próximas décadas hay que tener en cuenta la dinámica experimentada por los movimientos naturales de población; en este sentido, según un estudio realizado por el Instituto Económico de los Países Bajos, se prevé que ganarán población, principalmente, las regiones de la periferia maritima de la Comunidad, con lo que precisamente la población activa aumentará en las regiones menos favorecidas. Por lo cual, si la oferta de empleo no aumenta en la misma proporción que la demanda, estas regiones, que hoy día ven frenada su tradicional emigración, se verán afectadas por un grave aumento del paro y abocadas de nuevo a la emigración. En la actualidad, la tasa media de paro afecta a un 10,4 por 100 de la población activa de la Comunidad (1986).

A nivel nacional, los problemas más graves de paro los tienen España $(21,5 \%)$ e Irlanda $(18,7 \%)$, frente a Dinamarca y Luxemburgo, que ostentan los niveles más bajos $(6,7 \%$ y $2,5 \%$ respectivamente). Por otra parte, resulta sorprendente encontrar unas tasas de paro muy por debajo de lo que cabría esperar en Grecia y Portugal $(7,5 \%$ y $8,7 \%$ respectivamente); este hecho parece deberse al elevado porcentaje de empleo por cuenta propia en agricultura y servicios que se registra en estos países.

Si descendemos a un nivel regional, aunque todas las regiones se han visto afectadas por una progresión generalizada del paro, los índices más elevados coinciden en su gran mayoria con las regiones económicamente más atrasadas de la Comunidad -en las que además se suelen registrar las mayores tasas de crecimiento natural-, si bien no debemos olvidar todas aquellas regiones que en la actualidad padecen graves problemas de reconversión y que se encuentran afectadas por unas tasas de paro desproporcionadamente elevadas, como es el caso del Norte y Este de España, el Centro y Norte del Reino Unido, ciertas áreas de Bélgica y los Países Bajos, y algunas zonas del Ruhr y el Saar, asi como la región de Bremen, en la RFA, con un índice de paro muy superior a la media nacional $(10,1 \%$ en 1985) (Fig. 6).

La correlación del saldo migratorio con el paro a nivel nacional tiene una baja significación en la mayoría de los países, como ocurría con el PIB; coincidiendo las correlaciones significativas a nivel regional en los mismos países que en el caso anterior: RFA $(-0,50)$, Reino Unido $(-0,88)$ y Dinamarca $(0,92)$; aunque el signo de la correlación con respecto al paro es opuesto al de la correlación con el PIB en el Reino Unido y Dinamarca, manteniéndose la correlación negativa en el caso de la RFA. 
La situación generalizada de los sectores de actividad dentro de la CEE en el momento actual es de un descenso de los sectores primario y secundario y de un acusado incremento del sector sevicios. A nivel comunitario, un 11,2 por 100 de la población activa trabaja en el sector agrario, un 32 por 100 en la industria y un 56,8 por 100 en el sector servicios (1986).

Las regiones que registran una proporción más alta de población activa dedicada al sector primario se encuentran en las zonas central y occidental de la Península Ibérica, algunas regiones del Oeste y Sur de Francia, el Mezzogiono italiano, Grecia e Irlanda (Fig. 7). Analizando la evolución experimentada entre 1981-1985 en el sector I, se observa que, dentro del acusado descenso generalizado, algunas regiones (alrededor de un $30 \%$ ) han llegado a incrementar su población activa hasta en un 7,4 por 100 en Champagne-Ardenne (Francia) y en un 4,9 por 100 en Calabria (sector meridional italiano). Italia presenta en su sector agrario un marcado contraste en relación con otros países comunitarios: un 33 por 100 de sus regiones incrementan la población activa dedicada a este sector, al mismo tiempo que un 57 por 100 de las regiones aumentan su superficie cultivada en 226.900 Has. Este hecho, en relación con un saldo migratorio positivo, puede ser reflejo de la población de retorno tras la crisis industrial comunitaria.

El mayor porcentaje de población activa dedicada al sector II (Fig. 8) se observa en las regiones industriales tradicionales: sector central del Reino Unido (Blacks Countries), Francia septentrional y oriental (Nord-Pas-Calais, Lorraine, Alsace), Italia septentrional (Lombardía, Piemonte), sector noroeste de la Península Ibérica (País Vasco, Cataluña), o las regiones alemanas meridionales y de la cuenca del Ruhr. La evolución del sector secundario tan sólo es positiva aproximadamente en un 6 por 100 de las regiones estudiadas; de este porcentaje, Cataluña (España) es la que alcanza un mayor incremento de la población activa dedicada a este sector, con un aumento del 6,4 por 100 en el período analizado, seguida de Molise (Italia), donde se incrementa en un 4,5 por 100.

La proporción más alta de empleos en el sector III (Fig. 9) aparece claramente localizada en las grandes regiones metropolitanas de la Comunidad (región de Londres, Madrid, Paris, Roma, Randstadt Holland...) y en áreas turisticas (Costa Azul-Riviera, Córcega, Valle de Aosta...). El porcentaje de regiones que no siguen la tónica general de incremento se sitúa en torno al 6 por 100 , si bien este descenso es bastante insignificante en la mayoría de las regiones, excepto en Luxembourg (Bélgica), que desciende un 3,3 por 100 . En relación con años anteriores se observa un mayor incre- 
mento del empleo en el sector servicios, precisamente en aquellas regiones cuya participación en el empleo total era más baja.

Los resultados de la correlación entre los sectores de actividad y el saldo migratorio muestran un grado de asociación media tan sólo en tres países: en Bélgica en relación con el sector I $(0,44)$ y el sector $I 1(-0,46)$; en Francia en relación con el sector II $(-0,77)$ y el sector III $(0,45)$ y en España en relación con el sector III $(0,43)$.

Finalmente, la correlación de los movimientos migratorios con los distintos indicadores de calidad de vida, es más significativa en los países más desarrollados, lo cual resulta evidente si consideramos que, por lo general, la situación social de las regiones se encuentra ligada a sus fases de desarrollo económico. La motivación de la búsqueda de un mayor nivel de vida es una constante en los movimientos migratorios, al mismo tiempo que éstos tienden a reducir las disparidades regionales en este aspecto.

Así, observando los indicadores de consumo vemos la estrecha correlación que mantienen con el PIB (positiva); con el paro (negativa), y con los sectores de actividad (negativa con el sector agrario, y positiva con los sectores secundario y terciario).

Entre las distintas variables de consumo correlacionadas, la única que no mantiene ninguna correlación con los saldos migratorios es el consumo de electricidad, mientras que las restantes lo mantienen entre: un 16,6 por 100 de los paises para la variable de número de coches, hasta un 33,3 por 100 en la variable de TV, reflejándose en un 25 por 100 de los paises la correlación con las variables de teléfonos y motociclos.

Ordenados los países de mayor a menor consumo se aprecia una gran variación de unos indicadores a otros, tanto entre las regiones de un mismo país, como entre los distintos países. No obstante, se aprecia que los países que cuentan con un PIB superior al valor medio comunitario, están en los primeros puestos en cuanto a consumo de $\mathrm{Kwh} / \mathrm{hab}$.; y en su mayoría, también en los primeros puestos en cuanto al número de teléfonos, TV y coches, quedando en puestos inferiores en cuanto al consumo de motociclos.

Los indicadores de equipamiento y confort de las viviendas están considerados a nivel general entre los más importantes para conocer el nivel de vida de una población. Correlacionadas estas variables con los movimientos migratorios, vemos que existe una elevada correlación, manifestada en un 41,6 por 100 de los paises para la variable número de baños/ducha 
--RFA $(-0,82)$, Dinamarca $(-0,86)$, Reino Unido $(-0,65)$, Francia $(0,56)$, Países Bajos $(0,44)$-; en un 25 por 100 de los paises para la variable número de viviendas - Reino Unido $(0,85)$, Francia $(0,75)$, Dinamarca $(0,57)$-; y en un 16,6 por 100 de los países para la variable calefacción -Dinamarca $(-0,75)$, Reino Unido $(0,44)$ - (esta variable debe ser interpretada con sumo cuidado en su significado debido a las diferentes características climáticas que pueden enturbiar su interpretación). Al igual que en el caso anterior, el mayor nivel de equipamientos domésticos corresponde a los paises que cuentan con un PIB por encima de la media comunitaria.

Los indicadores de salud reflejan en líneas generales un cierto nivel de vida, o tal vez mejor, una cierta calidad de vida. En un 41,6 por 100 de los países hemos apreciado una significativa correlación con los movimientos migratorios en relación con alguna de las variables: negativa en el caso del Reino Unido con respecto a las variables número de médicos y de camas $(-0,5$ y $-0,63$ respectivamente) y Dinamarca $(-0,66$ número de médicos), y positivas en los casos de Francia $(0,56 ; 0,54$ y 0,52 en las variables de número de farmacéuticos, dentistas y camas de hospital respectivamente); Paises Bajos $(0,40$ y 0,67 en las variables de número de dentistas y número de camas) y Bélgica (0,56 en la variable de número de farmacéuticos). Asimismo, estos indicadores de equipamiento sanitario (sobre todo el de número de camas hospitalarias) quedan también en relación con otra serie de variables; positivamente con el PIB $(0,77)$, con el porcentaje de población dedicada al sectcr servicios $(0,53)$, con el consumo de electricidad $(0,41)$, con el número de abonados telefónicos $(0,72)$, con el número de coches $(0,62)$, y con el número de viviendas con calefacción central $(0,51)$, quedando correlacionados negativamente con el paro $(-0,62)$ y con el porcentaje de población dedicada al sector primario $(-0,63)$.

\section{CONSIDERACIONES FINALES}

Dado el momento de readaptación actual en muchos sectores; de la crisis generalizada a todos los niveles a pesar de los síntomas de reactivación económica que existen hoy dí; del aumento de los desequilibrios regionales tras la última ampliación comunitaria; y dadas las modificaciones apreciadas en la movilidad migratoria, no es fácil conocer con certeza cuál será la evolución de los movimientos migratorios para los próximos años y, 
por lo tanto, cuáles serán en este sentido las repercusiones que tendrá nuestra entrada en la CEE.

El momento actual, según hemos visto, parece manifestar una etapa de tránsito entre las últimas décadas de crisis y descenso de los movimientos migratorios y las décadas venideras, en que las proyecciones parecen indicar unas ciertas modificaciones en los flujos migratorios. No obstante, éstos variarán en función de cómo la política comunitaria pueda paliar los desequilibrios regionales, ya que tradicionalmente las migraciones han sido uno de los mecanismos reguladores de estos desequilibrios entre regiones pobres y regiones más prósperas dentro del complejo sistema socioeconómico; de cómo las regiones consigan crear suficientes puestos de trabajo para absorber la creciente demanda. En definitiva, de cómo todas y cada una de las regiones comunitarias logren alcanzar en todos los niveles los objetivos definidos en el Tratado de Roma. 


\section{BIBLIOGRAFIA}

COMISIÓN DE LAS COMUNIDADES EUROPEAS (1985): Orientaciones para una política comunitaria de las emigraciones.

COMMISION DES COMMUNAUTÉs EUROPÉENNES: Les programmes de developpement régional de la deuxième generation pour la période 1981-1985. Document.

Dominguez, Y. L. (Coordinador)(1985): Emigración y mercado común. Universidad Internacional Menéndez Pelayo. Instituto Español de Emigración.

Eurostat: Estadísticas de la Comunidad.

Fondo Europeo de DesarRollo REGIONAL. XI Informe Anual (1985). Comisión de las Comunidades Europeas.

Fondo Europeode Desarrollo Regional. XII Informe Anual (1986). Comisión de las Comunidades Europeas.

Las regiones de Europa (1985). Segundo informe periódico sobre la situación socioeconómica de las regiones de la Comunidad.

Las regiones de la Comunidad ampliada (1987). Tercer informe periódico por la Comisión sobre la situación y evolución socioeconómica de las regiones de la Comunidad. 


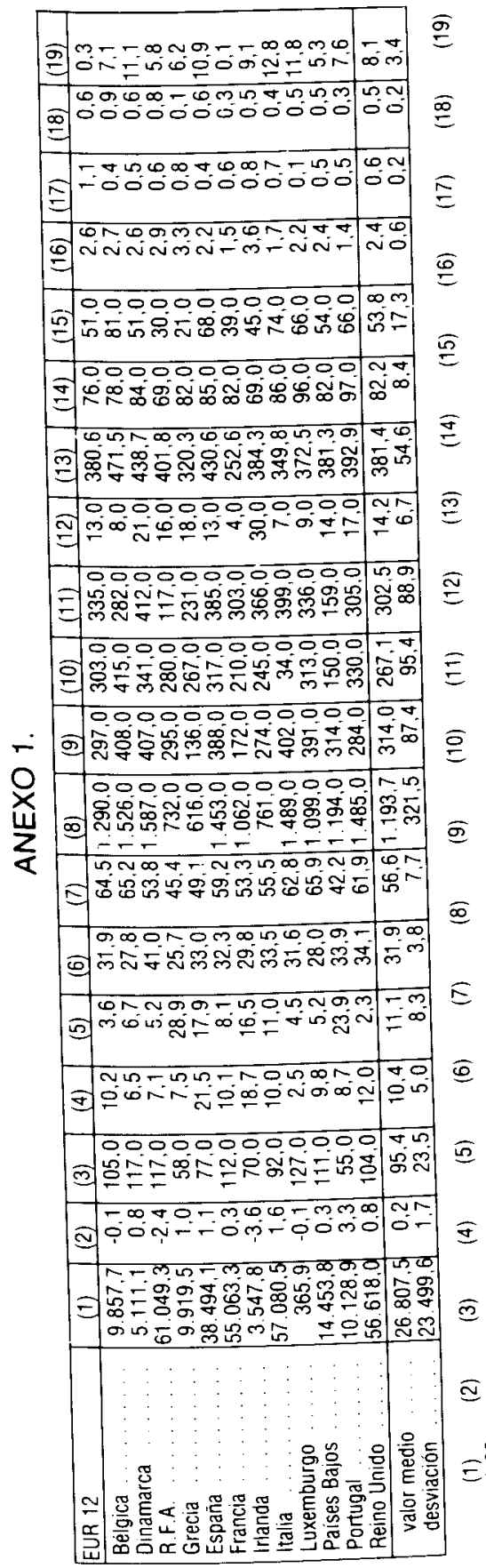

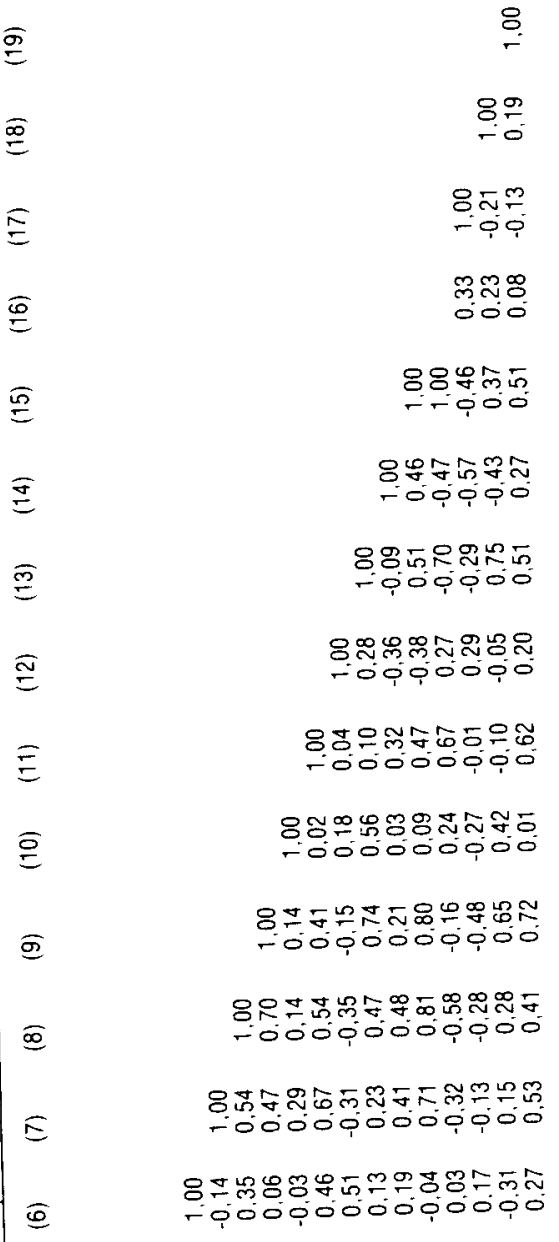

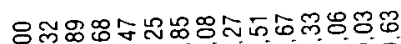
-iópió,

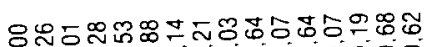

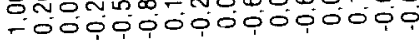

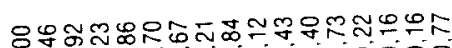
-íió,

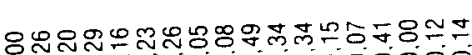

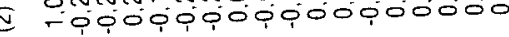

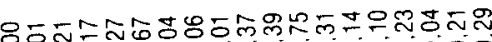
E-000

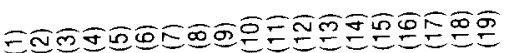

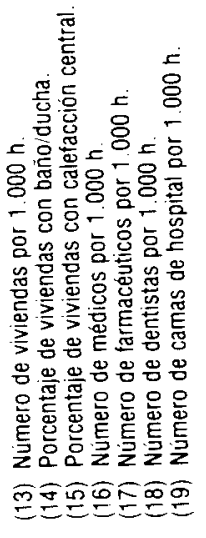

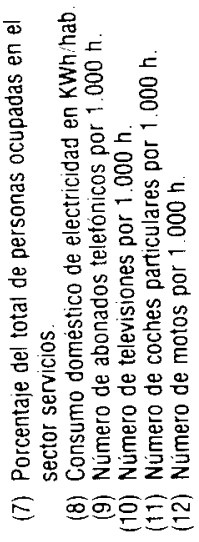

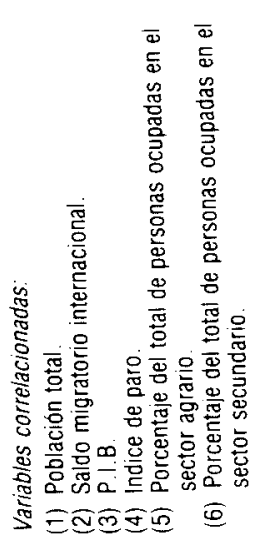




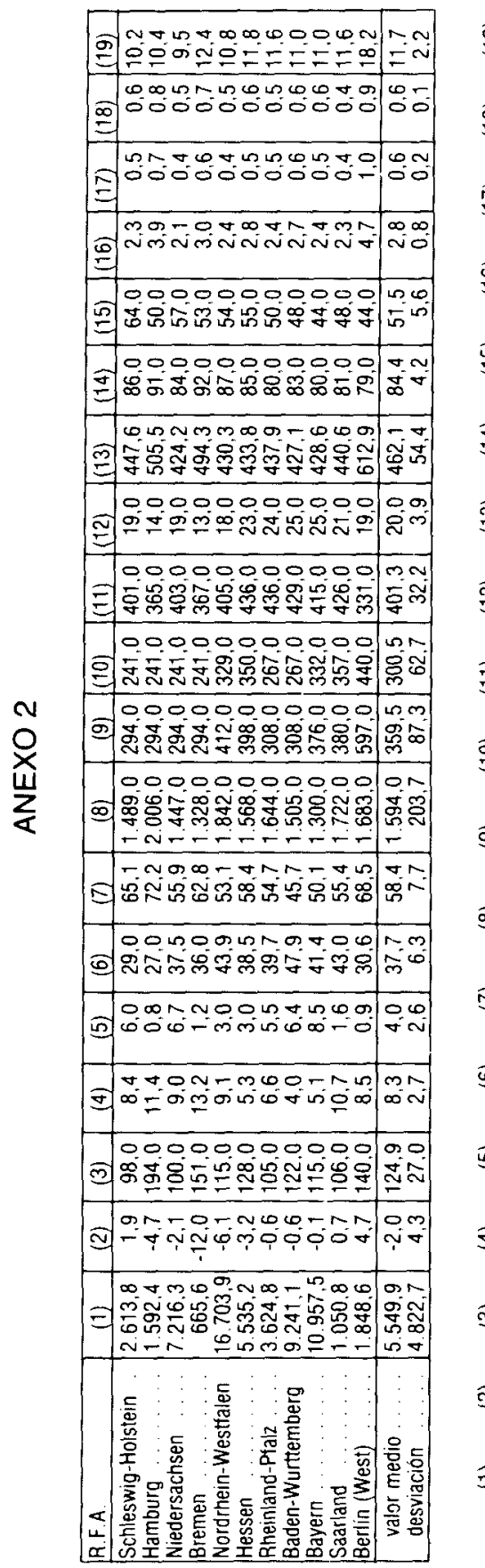

बิ

$\stackrel{800}{=} \quad \stackrel{800}{-\infty}$

$8 \% \infty$

E

$\widehat{\Phi}$

ชะูกล

$\div 00$

$\Xi$

ㅇํㅇำ

-

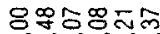

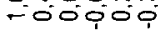

8万的苟舟品 -

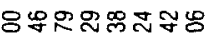
-

유뮴ำ -

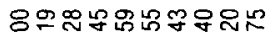
í0000000

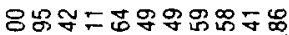
-0.000

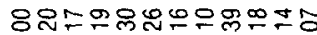
-

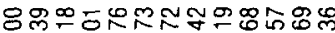

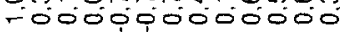

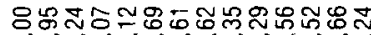

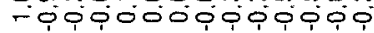

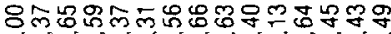

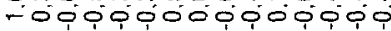

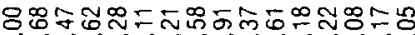

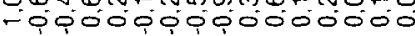

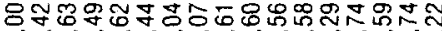

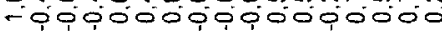

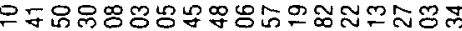

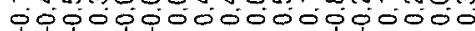

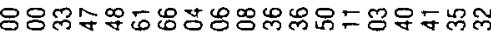
E-

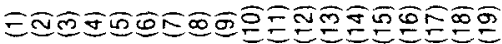




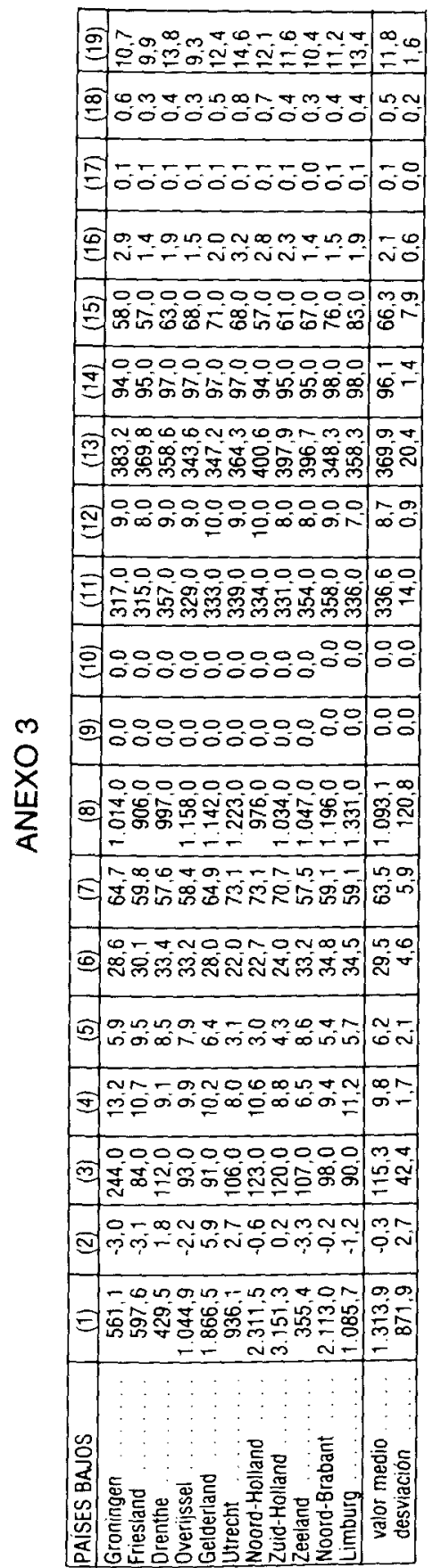

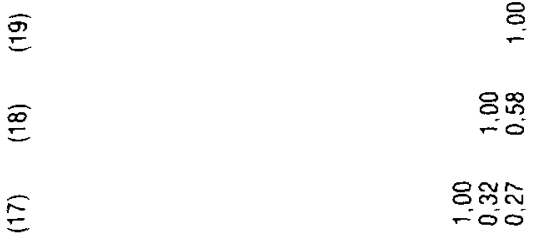

옹ํํำำ

-ió

8표요

-í⿴囗十

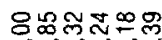
-0.000

용ํํำ윤 -

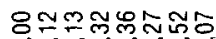

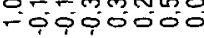

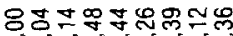
-0,

$\underline{E}$

$\widehat{\sigma}$

$\infty$

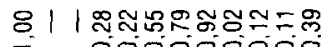

1111111111

11111111111

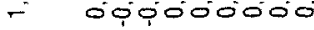

$E$

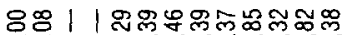
- i ióióió

토

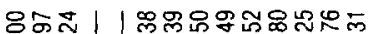
-

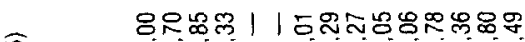

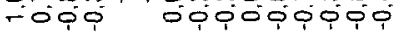

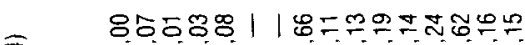

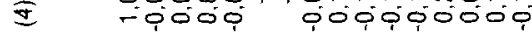

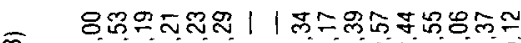

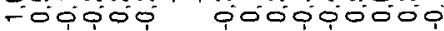

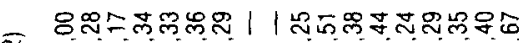

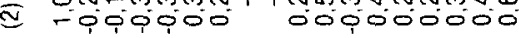

- 8

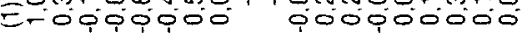

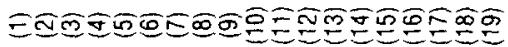

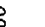

?




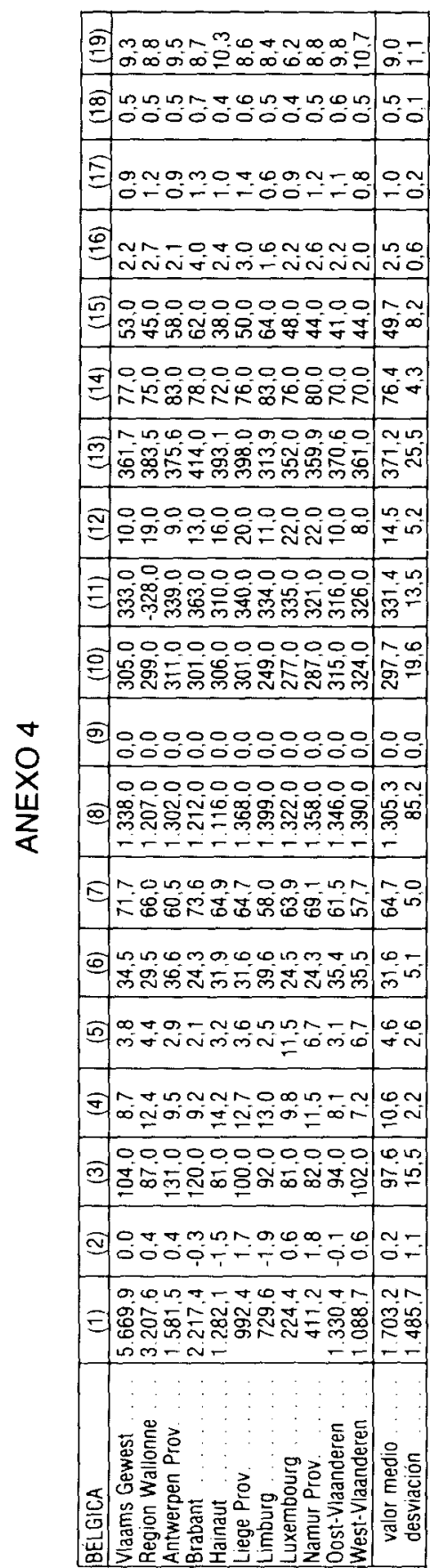

פ

$\stackrel{\infty}{=}$

$\underline{E}$

$\Phi$

$\stackrel{5}{=}$

$\stackrel{\Xi}{\Xi}$

$\widehat{\underline{2}}$

$\cong$

$\underline{E}$

을

क

$\infty$

$E$

6

ก

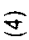

$\pi$

ำ

\section{8}

응

8융ํำ

-

830 Tó

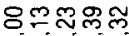
जo

8ำ영 - ÓTOOOO

8때요요 -

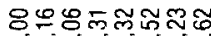
-000000

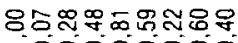
- 0000000

8ㄴำำ

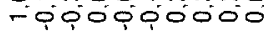

$11|1| 1|1| 1$

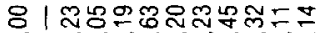
-

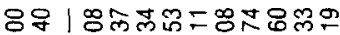
-

8人ิ -

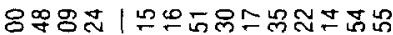

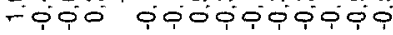

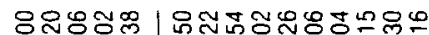

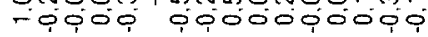

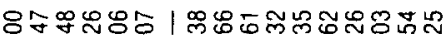
-0i000 000000000

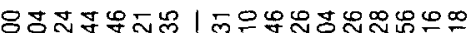

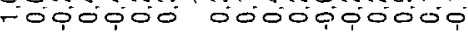

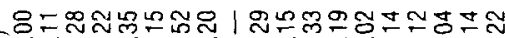

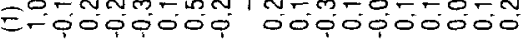

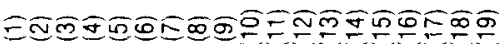




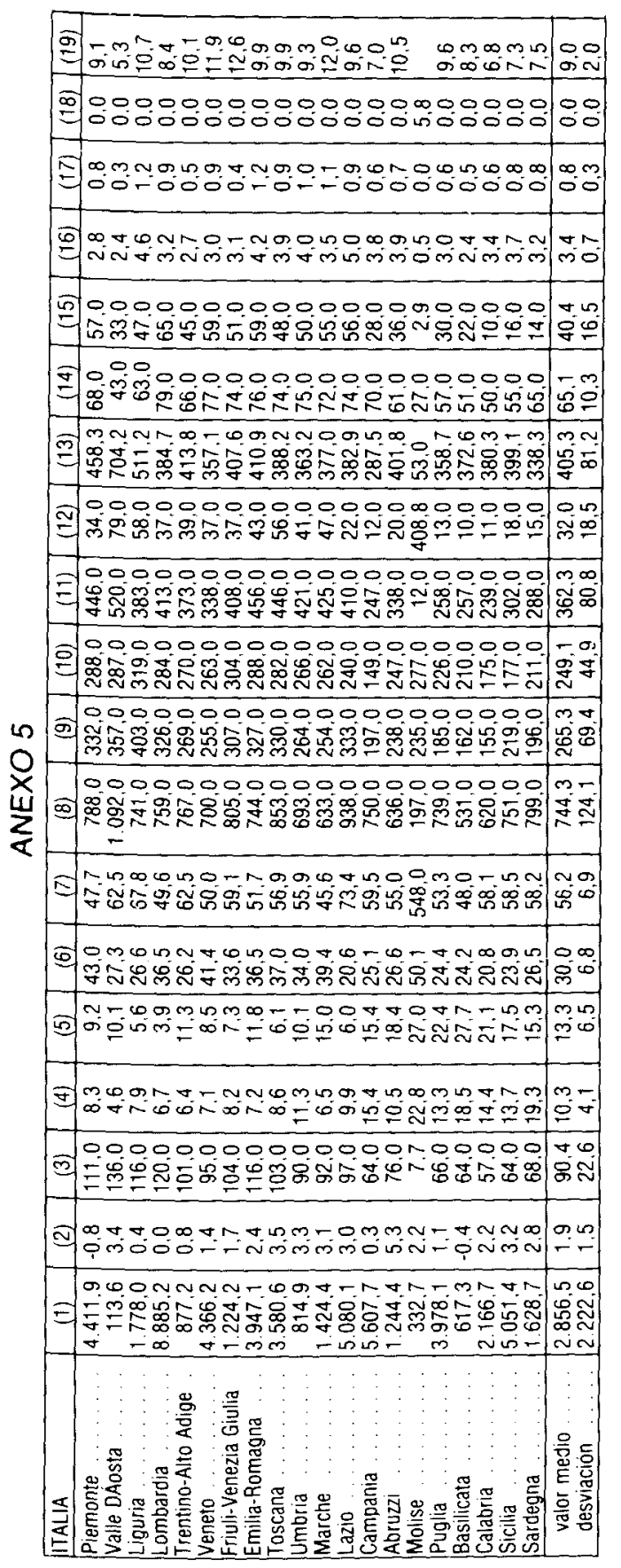

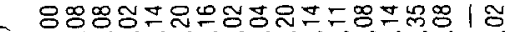

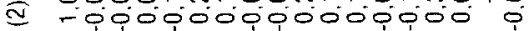

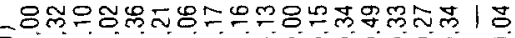
E-000000000000000

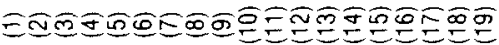
-OODOT

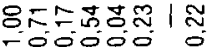

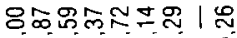
-000000

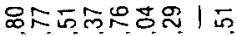

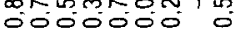

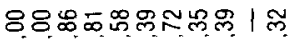
$\because 000000$

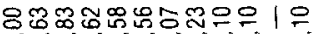
-00000000

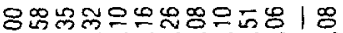

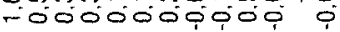

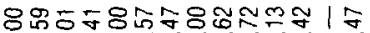
- 0000000000

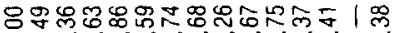

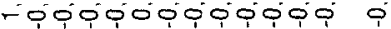

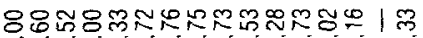
- opopiótióió

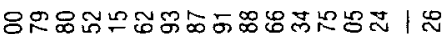
- 000000000000000 


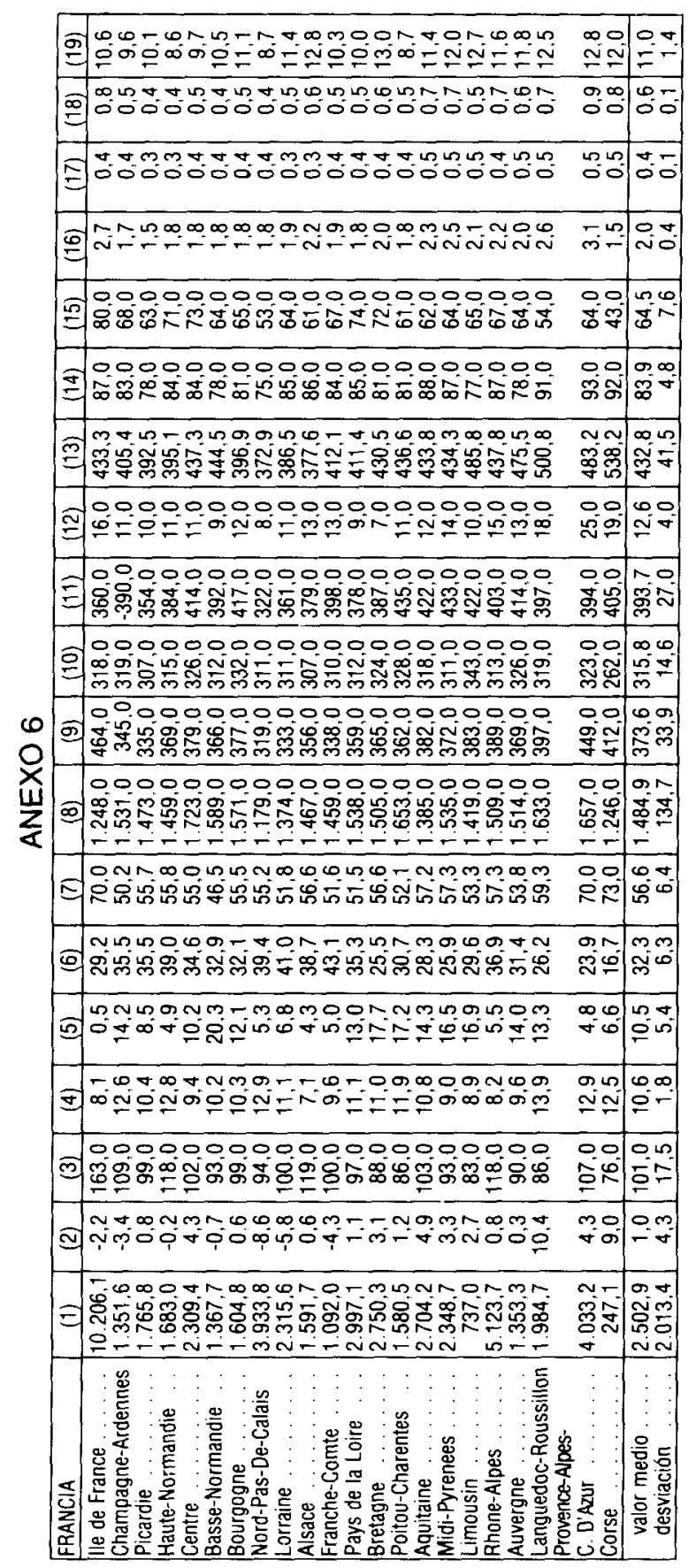

के

$\stackrel{\infty}{=}$

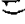

$\cong$

Ð0

$\sqrt{2}$

$\bar{\Xi}$

$\widehat{\underline{m}}$

$\cong$

$\equiv$

을

a

$\infty$

$E$

$\widehat{0}$

$\sqrt{2}$

于

3

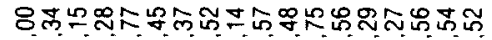
I -0000000000000000

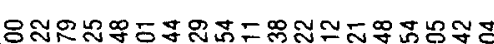
E-

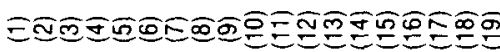

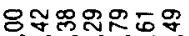
-0.0000

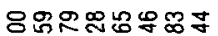
-0000000

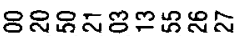
-ócióc00

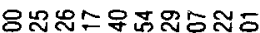
- ópió000

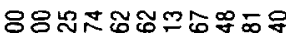
-000000000

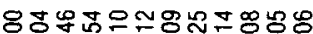
-0000000000

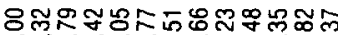
-

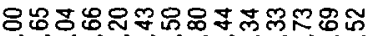
- ííiói

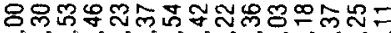

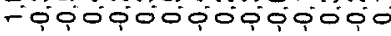

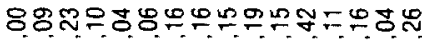

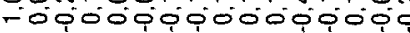

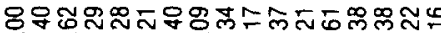

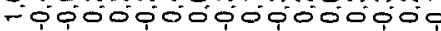




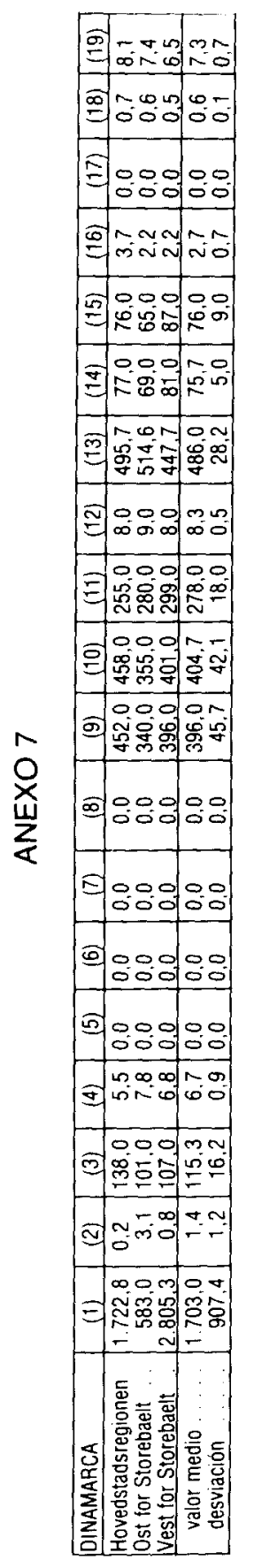

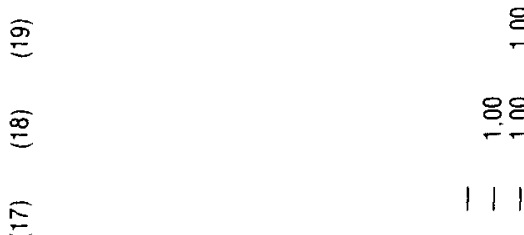

틀

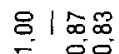

$\bar{E}$

881100

छ

8요 1

-

$\widehat{\underline{\Xi}}$

B.

$\widehat{\widehat{T}}$

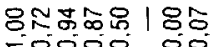
- 0 O.

E

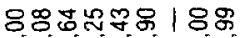

-0.

을

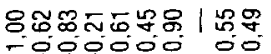

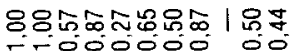

बㅇ

11111111111

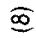

1111111111111

$\S$

$\bar{\Phi}$

11111111111111

$\sqrt[5]{5}$

111111111111111

× $\quad 811118880089815 \%$

文

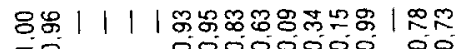

ल न0 00000000 00

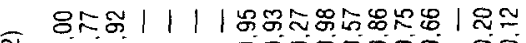

-

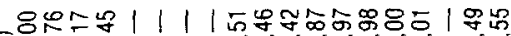

Erió oopióto ó

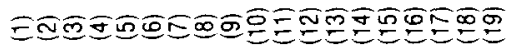

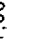

.

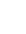




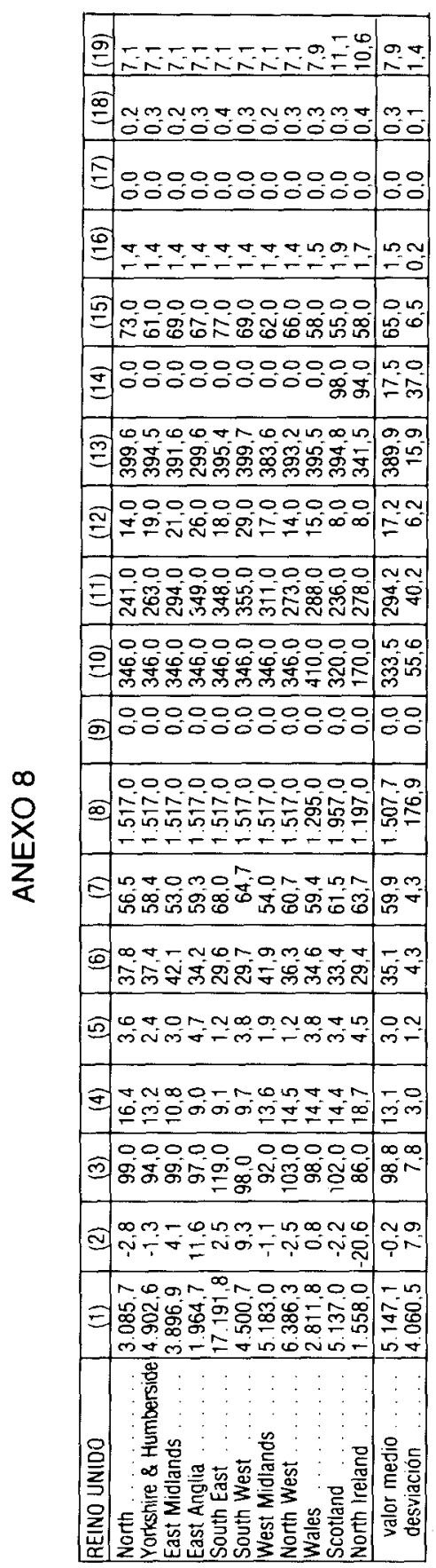

क

$\stackrel{\infty}{\underline{0}}$

$\Xi$

$\widehat{\theta}$

$\stackrel{5}{=}$

$\underline{\Xi}$

$\stackrel{\bar{m}}{巳}$

$\stackrel{\Xi}{\Xi}$

$E$

을

a

ळ

$\Xi$

$\underline{6}$

$\sqrt{2}$

$\Xi$

क

ธิ

- 8ำ

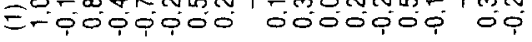

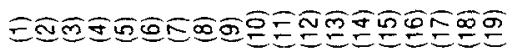

88180 - ب i

융ำ

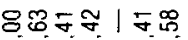
Tió

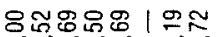
-OÓO

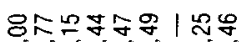

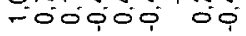

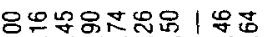
-00000

\section{| | | | | | | | | | 1}

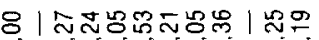

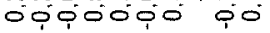

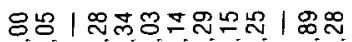
- póió0 00

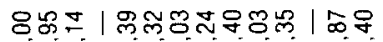

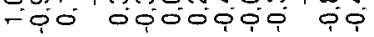

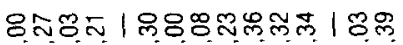
-íí

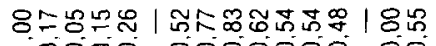

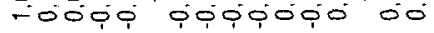

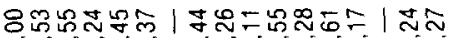

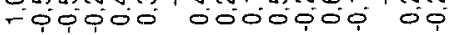

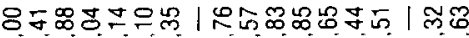

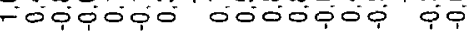




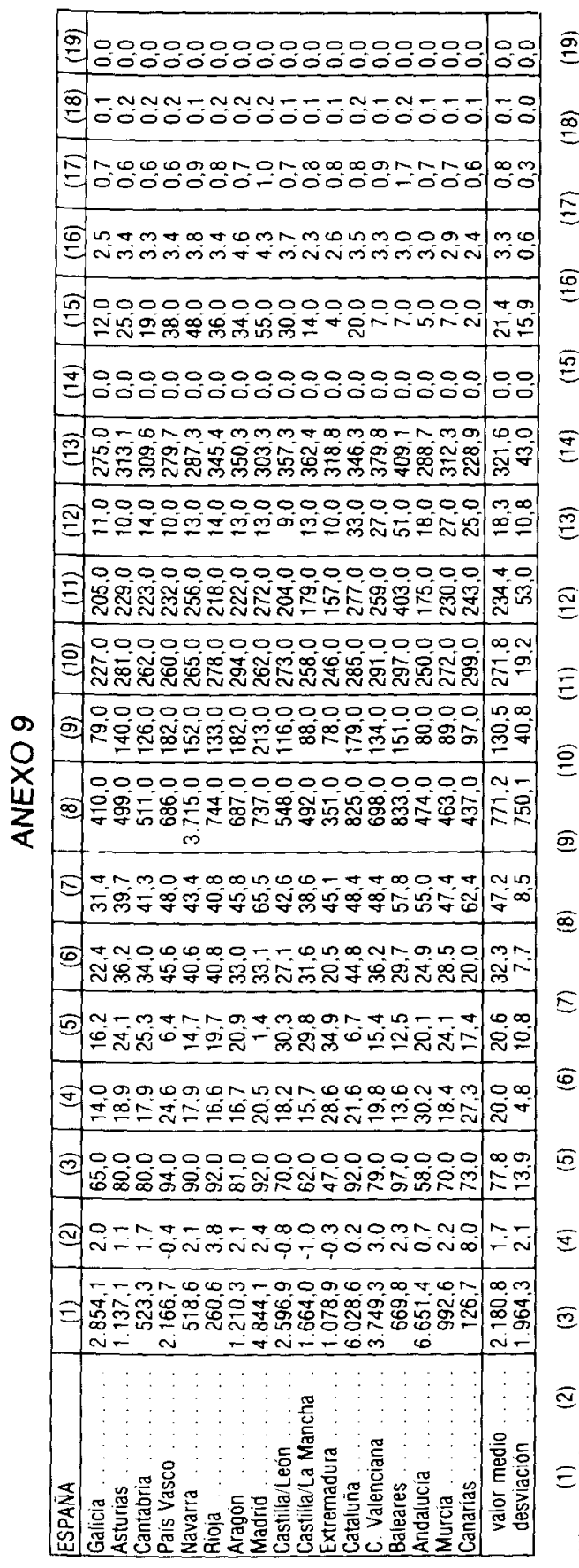

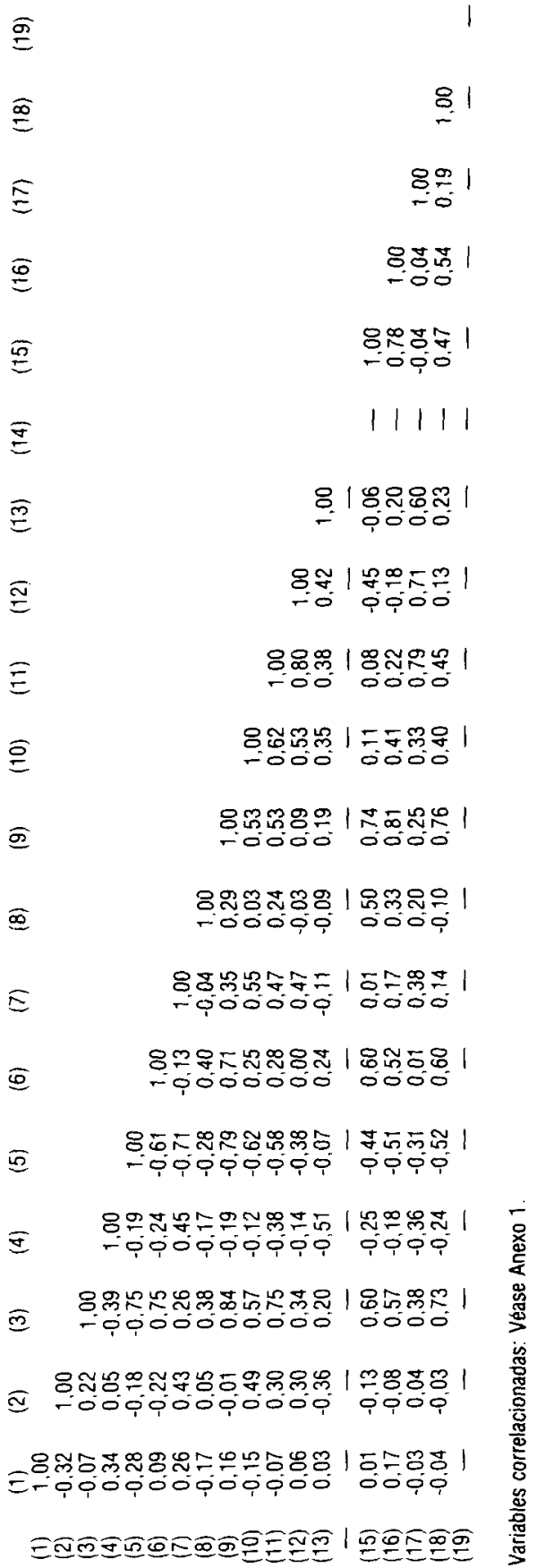




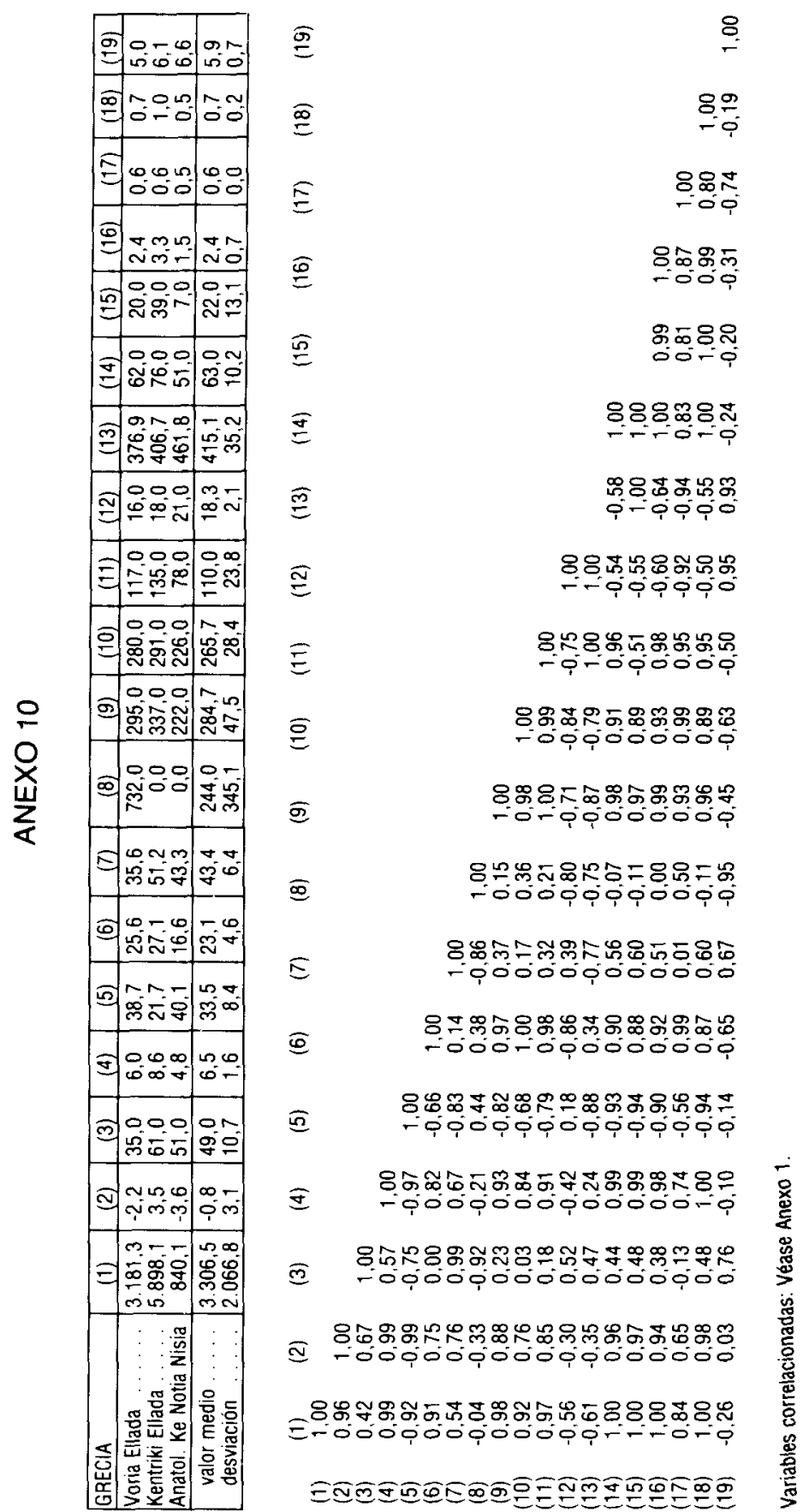




\section{Movimientos migratorios interregionales en la CEE}

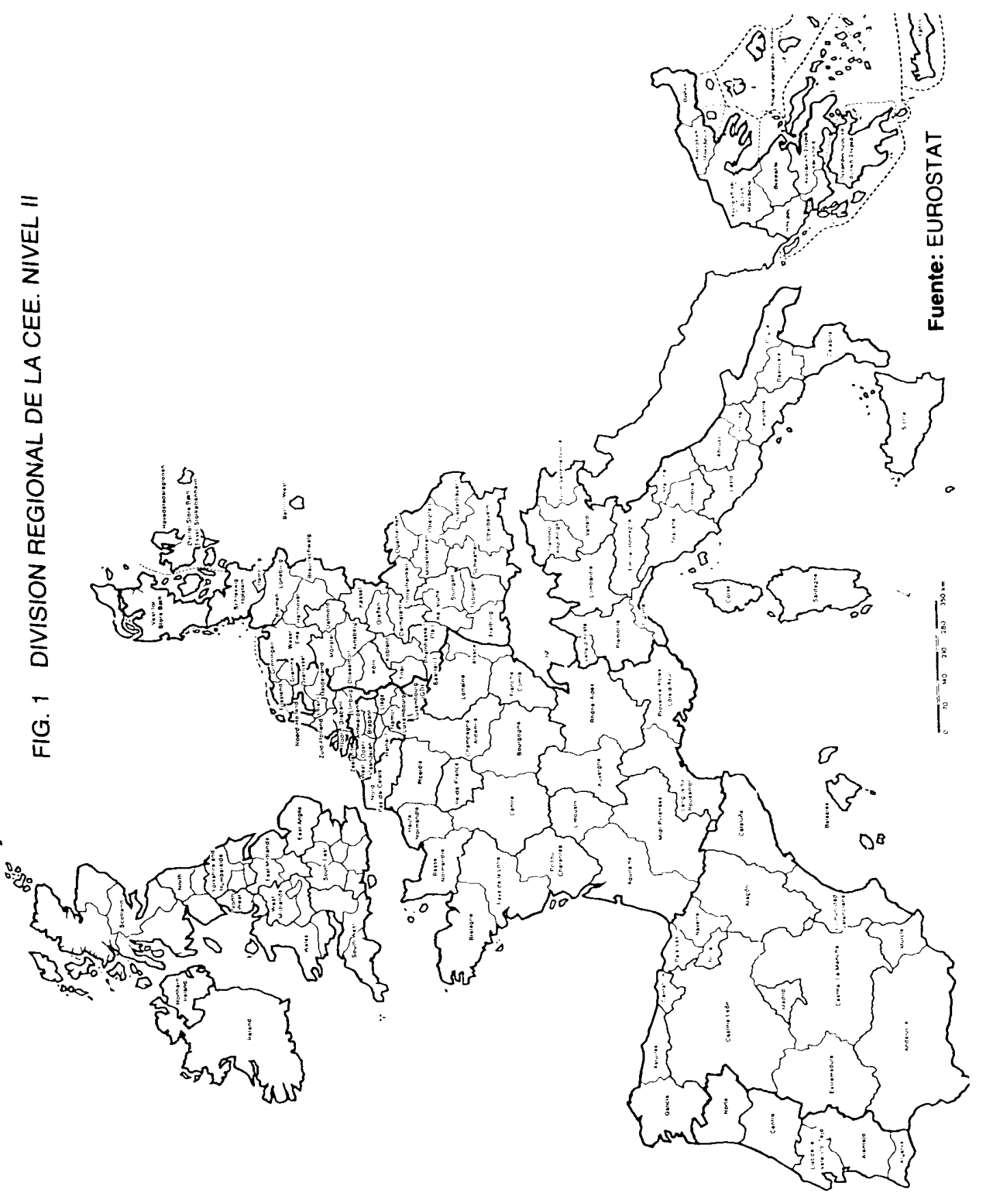


FIG. 2 EVOLUCION DEL SALDO MIGRATORIO EN LA CEE (1960-1985)

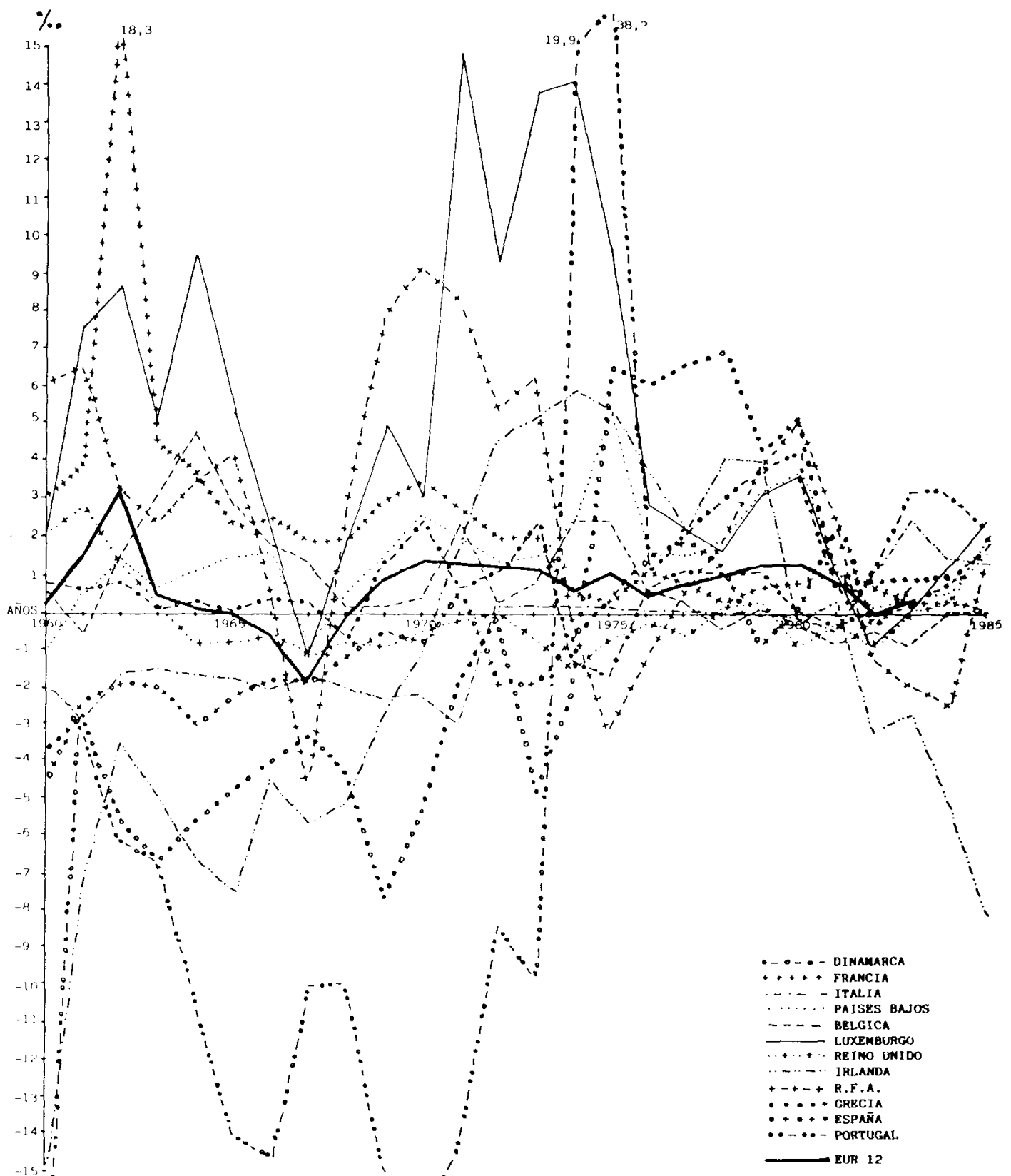

Fuente: EUROSTAT 
FIG. 3 PROCEDENCIA DE LA POBLACION INMIGRANTE EN LA CEE (1985)
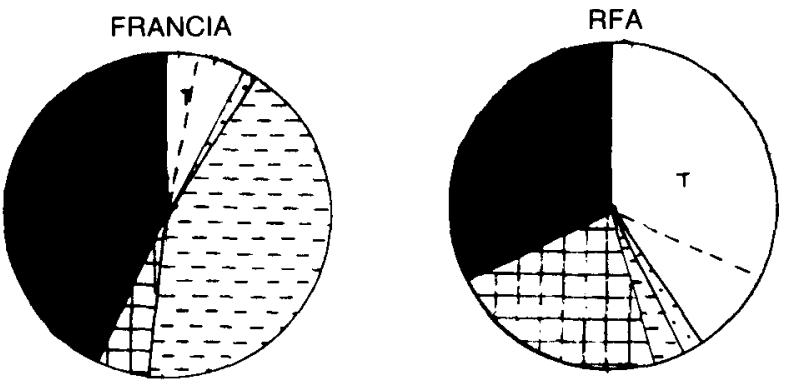

ค. UNIDO
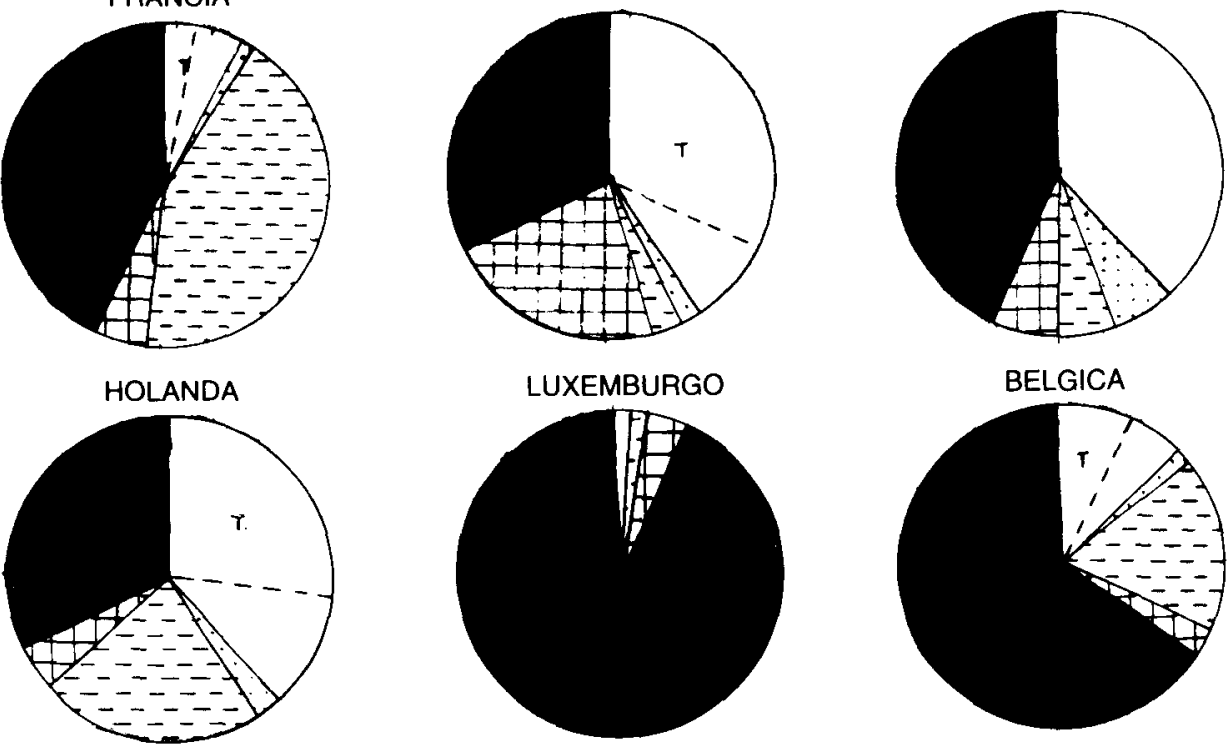

DINAMARCA
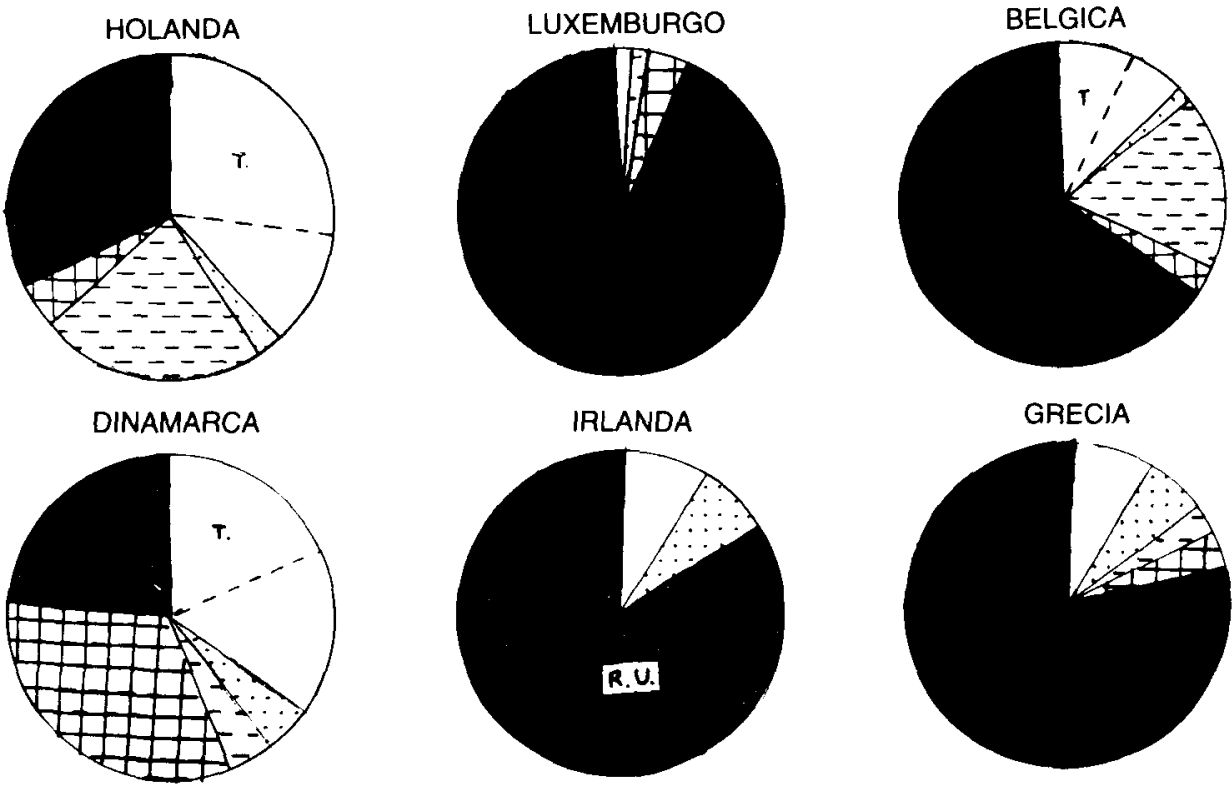

PORTUGAL
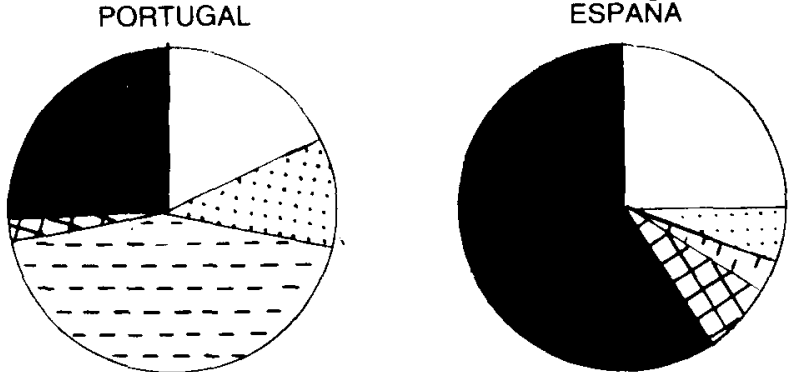

: P. Miembros

E: P. resto Europa

$\therefore$ : P. América del N

$E:$ P. Africanos

: Resto del mundo

$T$ : Turquia

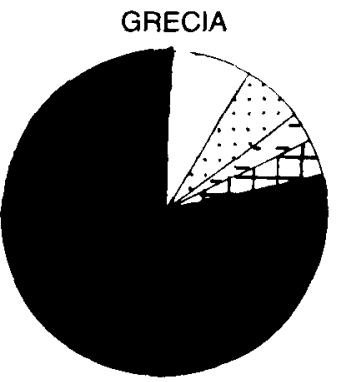

EUR 12

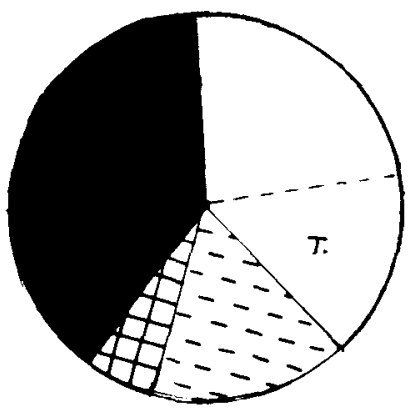

Fuente: EUROSTAT 


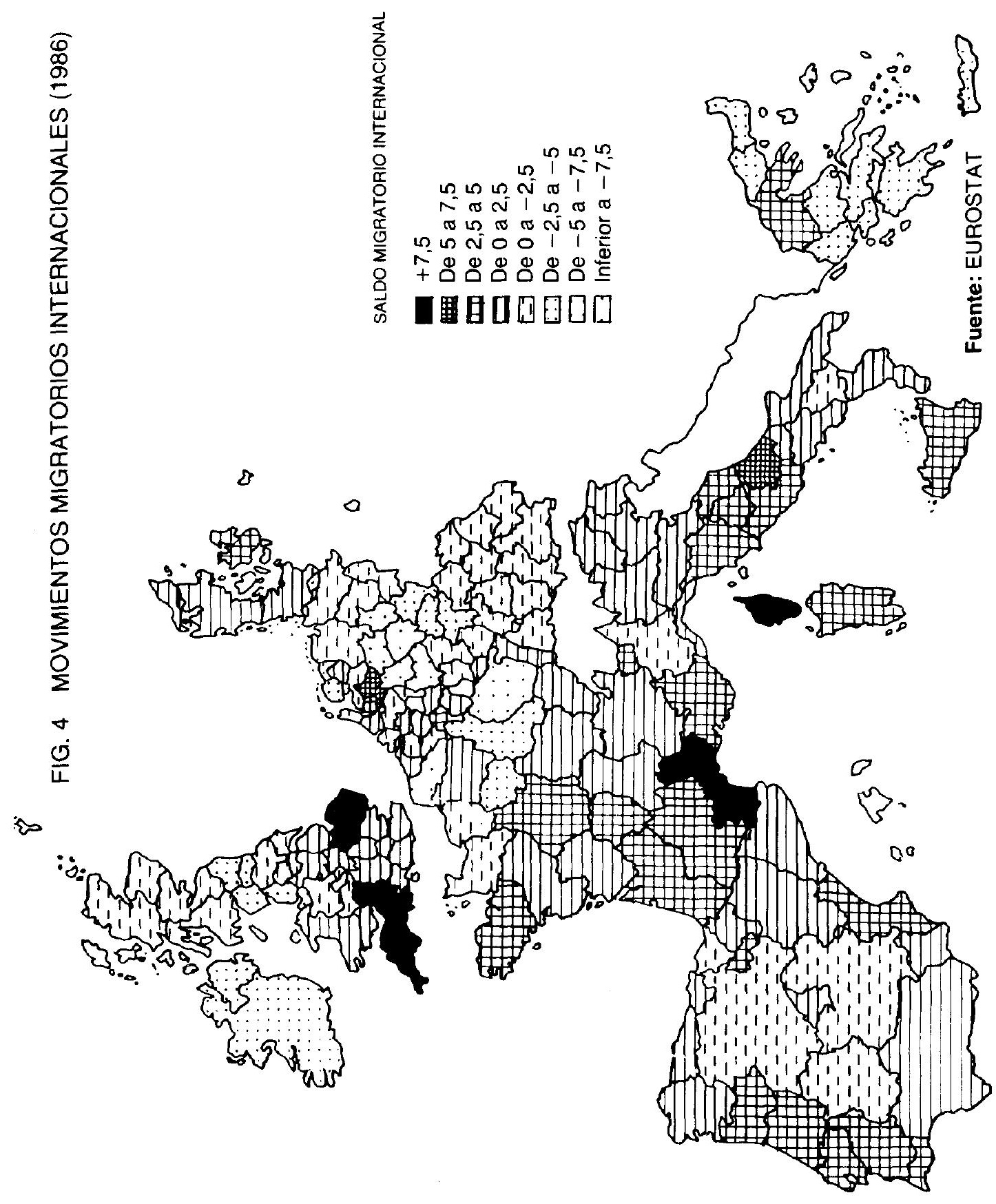




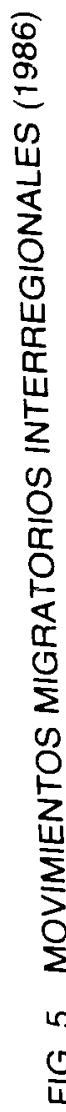

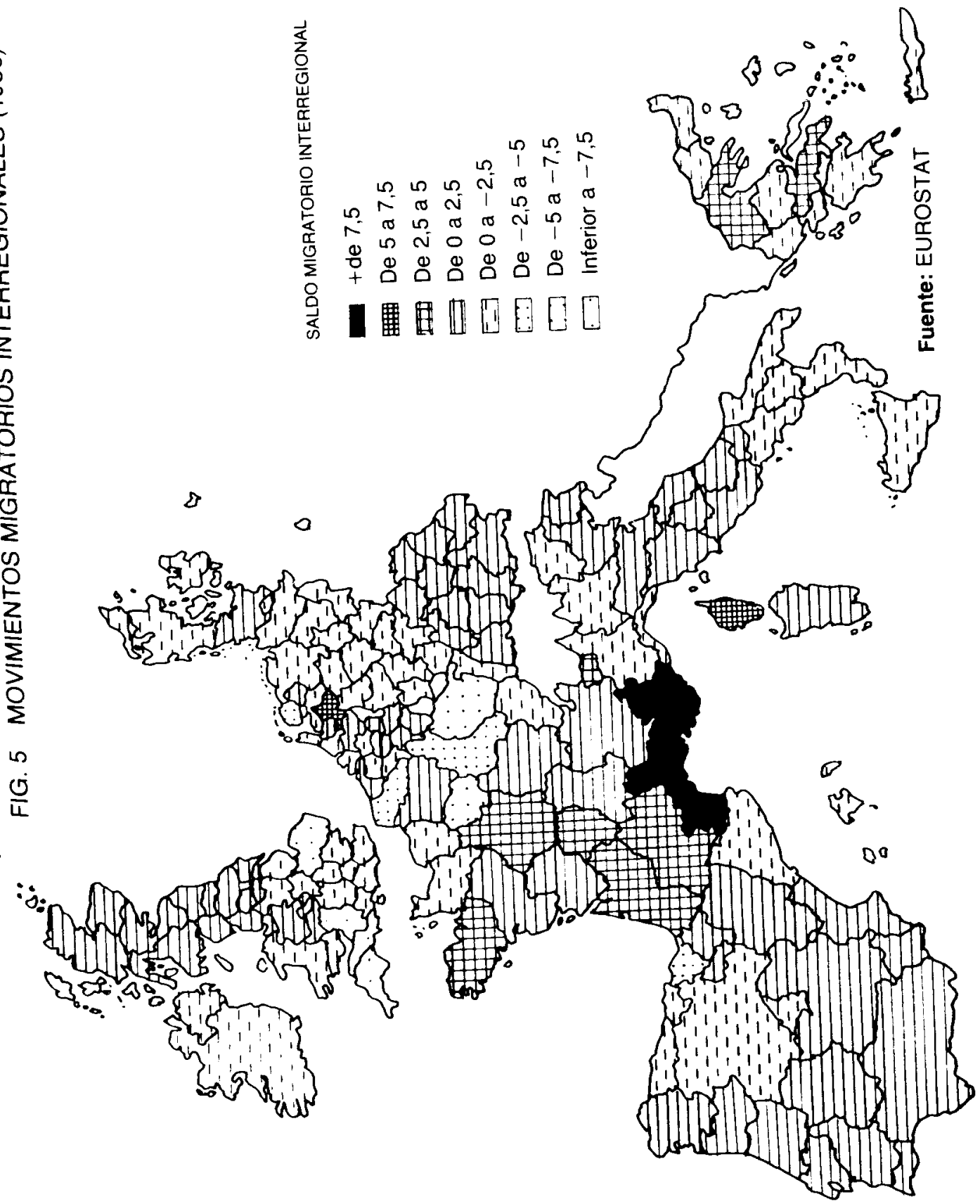

508080 


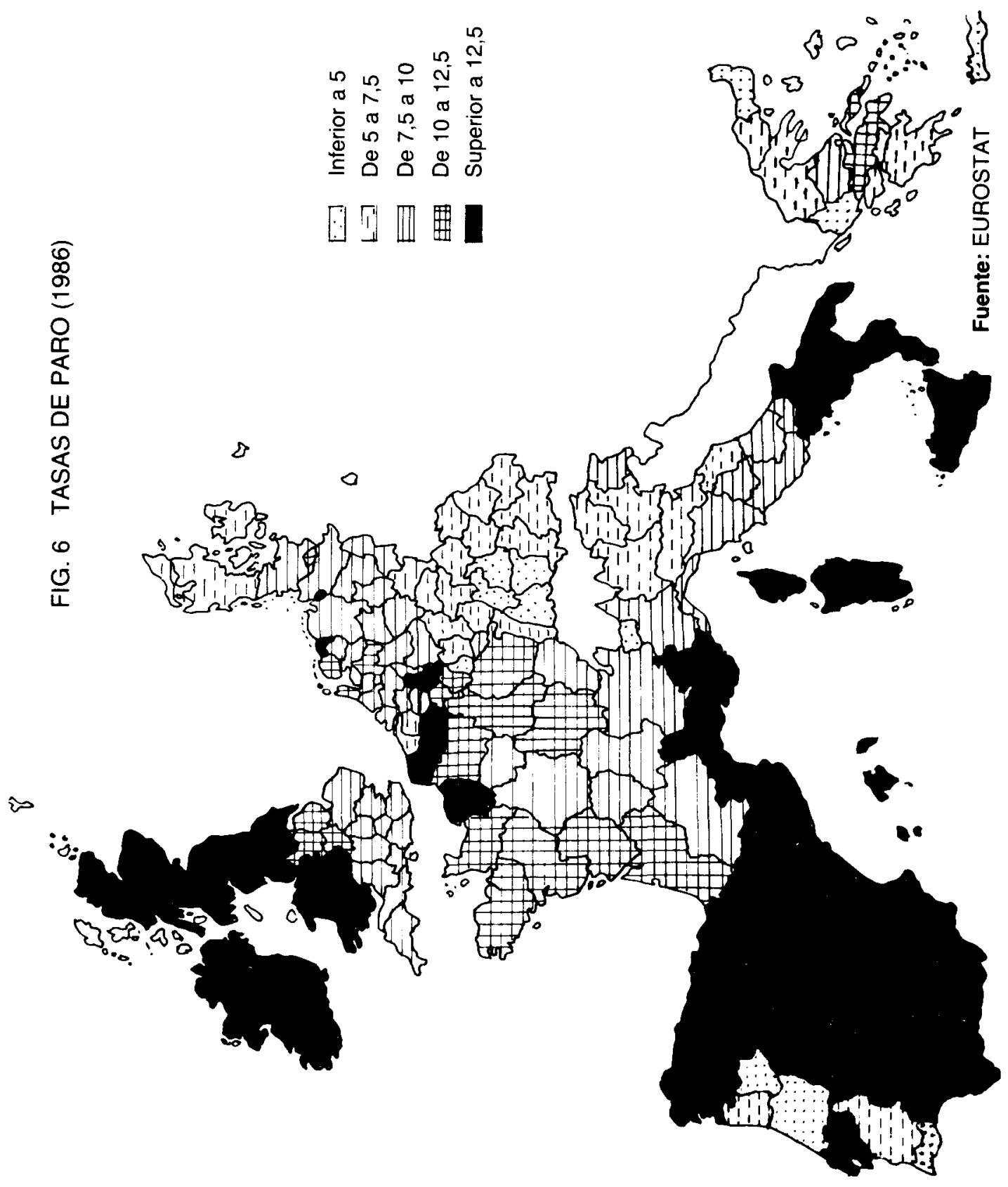




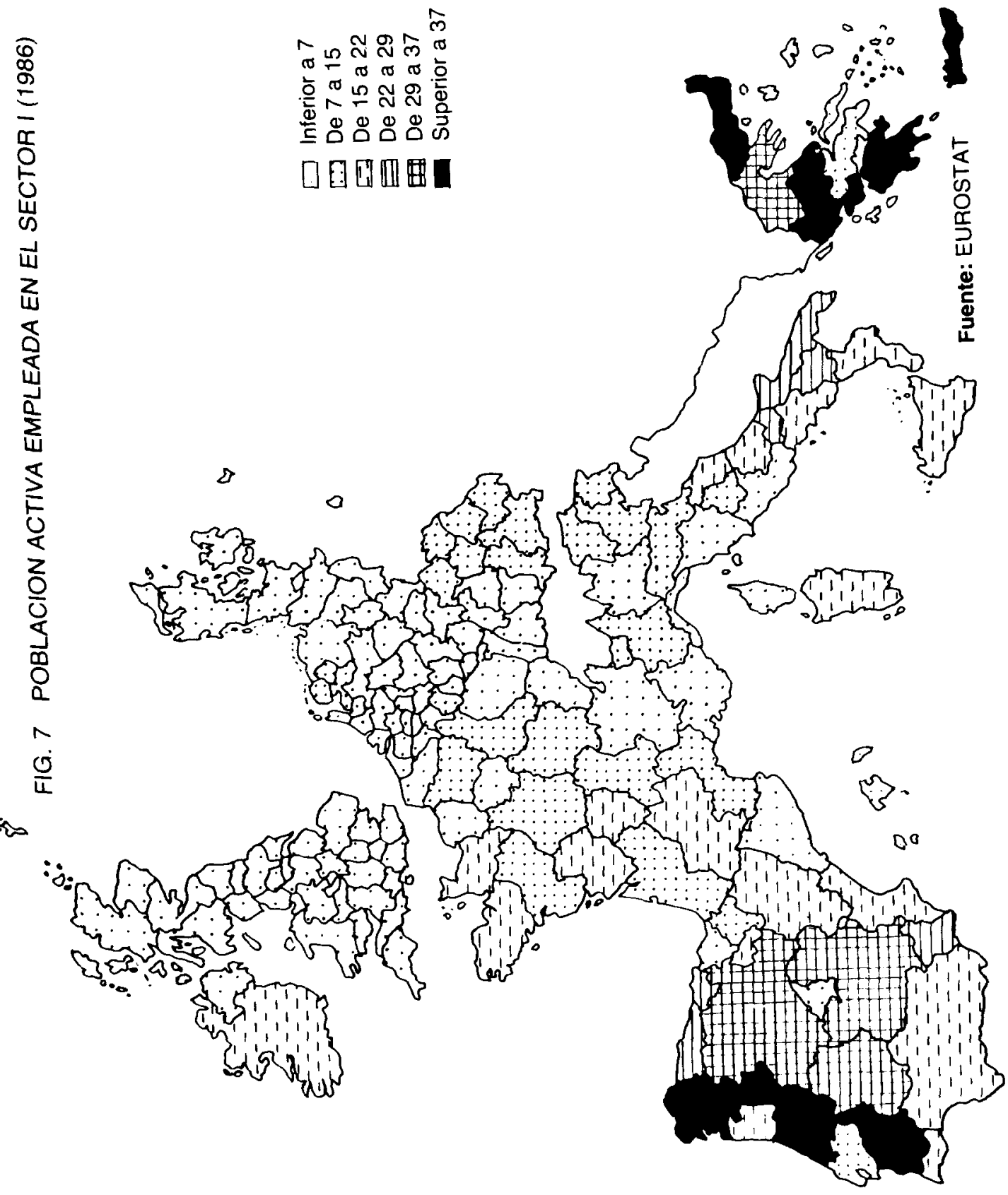




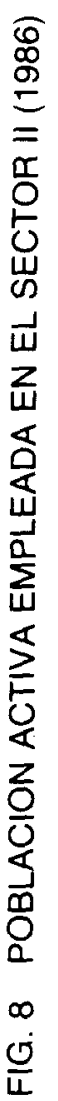

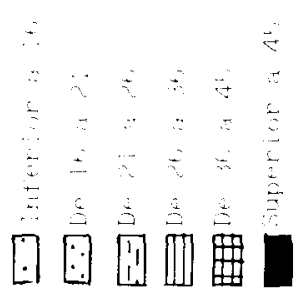

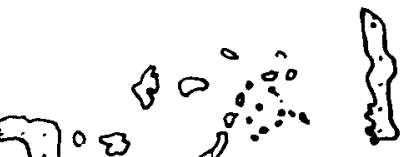

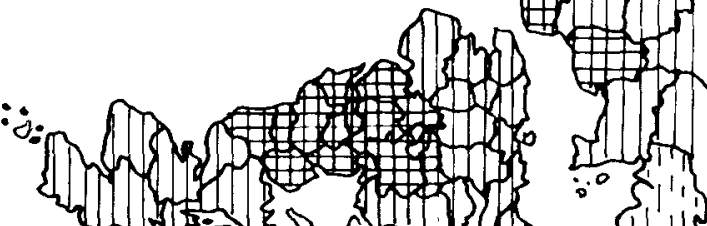

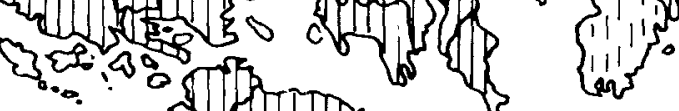
है।

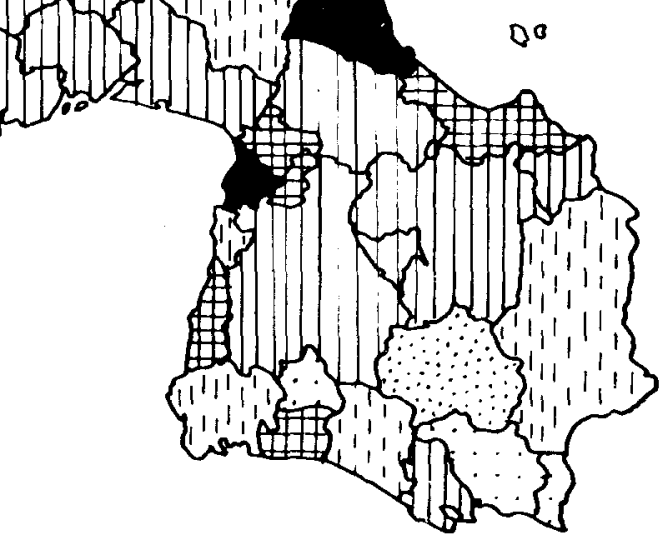




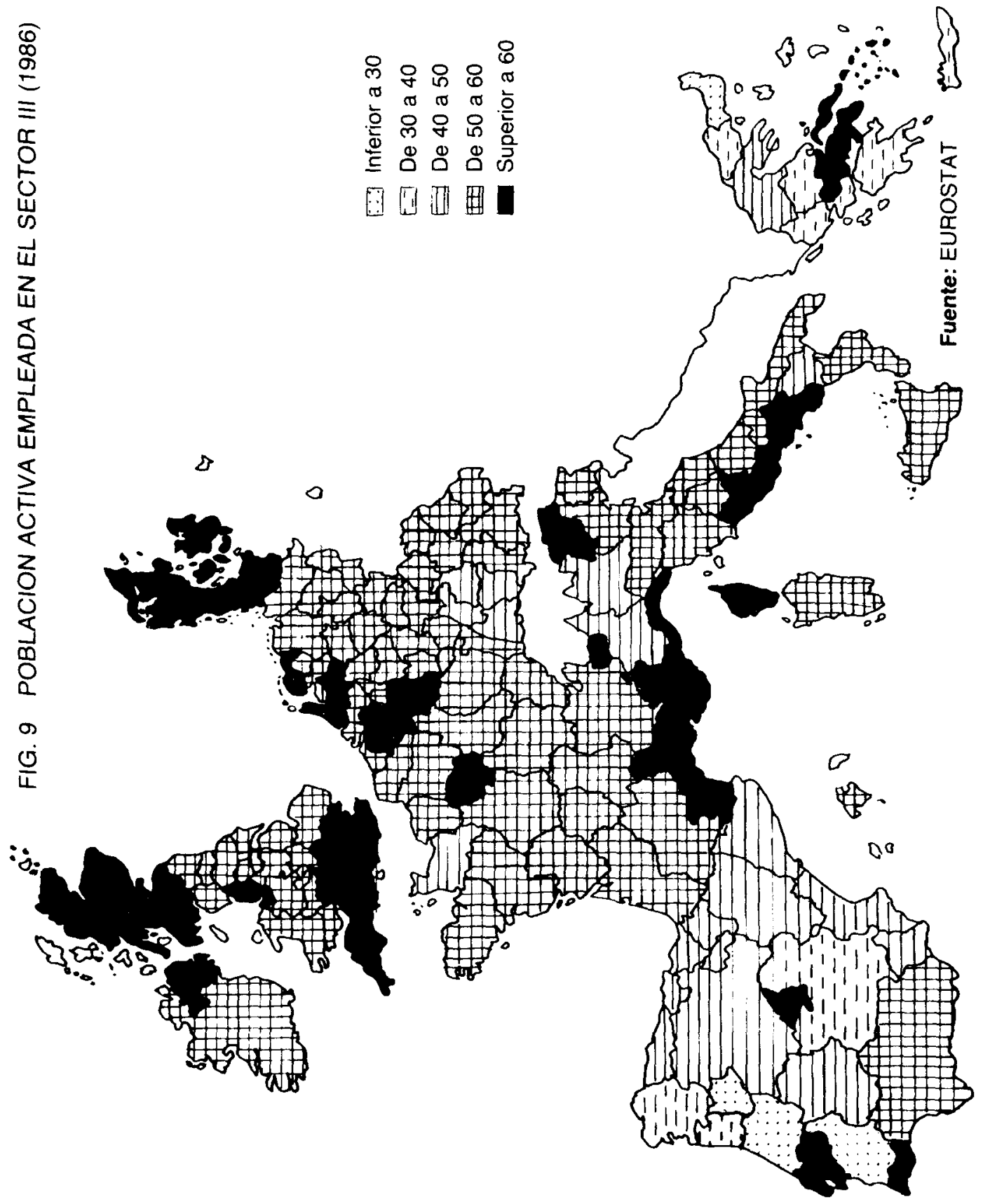

